\title{
Conservation, loss, and redeployment of Wnt ligands in protostomes: implications for understanding the evolution of segment formation
}

\author{
Ralf Janssen ${ }^{1 \dagger}$, Martine Le Gouar ${ }^{2 \dagger}$, Matthias Pechmann ${ }^{3 \dagger}$, Francis Poulin ${ }^{4,11}$, Renata Bolognesi ${ }^{5,12}$, \\ Evelyn E Schwager ${ }^{6}$, Corinna Hopfen7, John K Colbourne ${ }^{8}$, Graham E Budd', Susan J Brownn, Nikola-Michael Prpic ${ }^{3}$, \\ Carolin Kosiol', Michel Vervoort ${ }^{2,10}$, Wim GM Damen ${ }^{9^{*}}$, Guillaume Balavoine ${ }^{2,10^{*}}$, Alistair P McGregor ${ }^{7 *}$
}

\begin{abstract}
Background: The Wnt genes encode secreted glycoprotein ligands that regulate a wide range of developmental processes, including axis elongation and segmentation. There are thirteen subfamilies of Wht genes in metazoans and this gene diversity appeared early in animal evolution. The loss of Wnt subfamilies appears to be common in insects, but little is known about the Wnt repertoire in other arthropods, and moreover the expression and function of these genes have only been investigated in a few protostomes outside the relatively Wnt-poor model species Drosophila melanogaster and Caenorhabditis elegans. To investigate the evolution of this important gene family more broadly in protostomes, we surveyed the Wht gene diversity in the crustacean Daphnia pulex, the chelicerates Ixodes scapularis and Achaearanea tepidariorum, the myriapod Glomeris marginata and the annelid Platynereis dumerilii. We also characterised Wnt gene expression in the latter three species, and further investigated expression of these genes in the beetle Tribolium castaneum.

Results: We found that Daphnia and Platynereis both contain twelve Wnt subfamilies demonstrating that the common ancestors of arthropods, ecdysozoans and protostomes possessed all members of all Wnt subfamilies except Wnt3. Furthermore, although there is striking loss of Wnt genes in insects, other arthropods have maintained greater Wnt gene diversity. The expression of many Wht genes overlap in segmentally reiterated patterns and in the segment addition zone, and while these patterns can be relatively conserved among arthropods and the annelid, there have also been changes in the expression of some Wnt genes in the course of protostome evolution. Nevertheless, our results strongly support the parasegment as the primary segmental unit in arthropods, and suggest further similarities between segmental and parasegmental regulation by Wnt genes in annelids and arthropods respectively.
\end{abstract}

Conclusions: Despite frequent losses of Wht gene subfamilies in lineages such as insects, nematodes and leeches, most protostomes have probably maintained much of their ancestral repertoire of twelve Wnt genes. The maintenance of a large set of these ligands could be in part due to their combinatorial activity in various tissues

\footnotetext{
* Correspondence: wim.damen@uni-jena.de; balavoine.guillaume@ijm.univparis-diderot.fr; alistair.mcgregor@vetmeduni.ac.at

† Contributed equally

${ }^{2}$ Centre de Génétique Moléculaire du CNRS, FRE 3144, avenue de la Terrasse

91198 Gif-sur-Yvette, France

${ }^{7}$ Institut für Populationsgenetik, Veterinärmedizinische Universität Wien,

Veterinärplatz 1, A-1210, Vienna, Austria

Full list of author information is available at the end of the article
} 


\section{Background}

Wnt signalling regulates many developmental processes in metazoans, including cell proliferation, migration and pattern formation [1]. The Wnt genes encode secreted glycoprotein ligands that bind to various transmembrane receptors thereby triggering intracellular cascades, including the $\beta$-catenin pathway, to regulate transcription in target cells [2].

Among protostomes, Wnt signalling has been most intensively studied in the nematode worm Caenorhabditis elegans and the fly Drosophila melanogaster. These two model ecdysozoans have five and seven $\mathrm{Wnt}$ genes respectively [3-13], which generally reflects the number of Wnt genes found in insects with sequenced genomes [14-16]. However, thirteen subfamilies of Wnt genes have been reported in metazoans [17-19]. All thirteen subfamilies are found in deuterostomes, although WntA may have been lost in vertebrates and other lineages [18-20]. Twelve subfamilies have also been recently reported in lophotrochozoans, which is evidence for a large set of Wht genes ancestrally in protostomes [17]. This complexity in the repertoire of Wnt genes appeared very early in metazoan evolution because twelve subfamilies are also found in the cnidarians Nematostella vectensis and Hydra magnipapillata [18,21,22]. Taken together, these earlier studies demonstrate striking patterns of Wht gene loss in insects and Caenorhabditis in comparison to other animals. However, it is not yet known if this loss of Wht genes is a derived feature of insects or a more general characteristic of arthropods (or ecdysozoans). Moreover, our understanding of the evolution of the Wnt gene family is hampered by the paucity of expression and functional studies in arthropods and protostomes other than Drosophila and Caenorhabditis [14,17,23-25].

A major exception to this paucity of knowledge is wingless (wg/Wnt1). Among many other roles in Drosophila, $w g$ functions as a segment polarity gene to specify and maintain boundaries and cell fates across the primary segmental units or parasegments [3,9,26-29]. $w g$ is expressed at the posterior boundary of each parasegment directly juxtaposed to cells expressing engrailed (en) at the anterior parasegmental boundary. Studies of $w g$ and $e n$ in other arthropods indicate that their delineation of parasegmental boundaries is an ancestral feature of these animals [30-34]. Furthermore, the expression of the $w g$, en and $h h$ homologues also delimits segmental boundaries in the annelid, Platynereis dumerilii: a representative of lophotrochozoans, the large sister-clade of the ecdysozoans within protostomes $[35,36]$. This observation suggests that the wg-en regulatory system was either independently recruited for segment boundary determination in annelids and arthropods or is plesiomorphic with respect to a segmented common ancestor. This debate [37-39] could be resolved by comparing the expression of other genes involved in segmentation within and among arthropods and annelids. Intriguingly, segmental expression of several other $W n t$ genes has been observed in various arthropods, suggesting that these $W n t$ genes may also be involved in segmentation [23,24,30,33].

To investigate the Wnt repertoire of arthropods and protostomes more broadly, we surveyed the Wnt genes found in a crustacean, the water flea Daphnia pulex, a myriapod, the millipede Glomeris marginata, two chelicerates, the spider, Achaearanea tepidariorum and the tick, Ixodes scapularis, and an annelid, the polychaete worm Platynereis dumerilii. We then characterised the expression of Wnt genes in Achaearanea, Glomeris, Platynereis, and Tribolium to compare the possible roles of Wht genes in segmentation and other developmental processes among the arthropods, and protostomes generally.

Our survey and analysis of Wht genes demonstrates that the common ancestor of arthropods contained twelve of the thirteen subfamilies, and, therefore, that the ancestral protostome contained all Wnt gene subfamilies except $W n t 3$ as was previously suggested by data from lophotrochozoans [17]. We found twelve, eleven and ten Wnt genes in Daphnia, Achaearanea and Ixodes respectively, including orthologues of Wnt2 and Wnt4, which are not found in insects. This shows that the loss of $W n t$ genes observed in insects is not a general feature of arthropods.

We found that many Wnt genes are expressed in segmentally reiterated patterns in protostomes. For example, Wnt10 and Wnt16, and wg, are expressed in similar segmental patterns in arthropods and in the annelid Platynereis. However, we also found taxon-specific segmental expression of several Wnt genes, even among the arthropods. This pattern of conservation and redeployment of Wnt genes expressed in segmentally reiterated patterns in arthropods and the annelid was also reflected in the expression of these genes in the posterior 
segment addition zone (SAZ) [31,40,41] (hereafter we use this more general term rather than 'growth zone' as commonly used for arthropods, see Discussion), appendages, nervous system and other tissues. Indeed, the overlapping expression of multiple Wnt genes in the same tissues supports the hypothesis that Wnt signalling operates through a combinatorial code of different Wnt ligands [42].

\section{Methods}

\section{Wnt gene sequences}

Members of the Wnt subfamilies, 1, 2, 5, 7, 8, A and 16, were previously isolated from Achaearanea or Cupiennius, and subfamilies 1, A and 16 from Glomeris (Additional file 1). Note that Glomeris Wnt16 and WntA were previously erroneously characterised as $W n t 7$ and $W n t 5$ orthologues respectively [33]. We obtained sequences of a further four Wnt genes from both Achaearanea and Glomeris using degenerate PCR with embryonic cDNA template. The sequences of degenerate primer pairs used to isolate Wnt genes are shown in Additional file 2. Larger fragments of initial PCR fragments were obtained via RACE PCR using the Marathon RACE Kit (Clontech). RNA isolation from spiders and Glomeris, and cDNA synthesis was carried out as described previously $[33,43]$.

For Daphnia, known Wnt gene sequences were obtained from GenBank and protein sequences were used to perform tblastn searches of assembled genomic scaffolds, predicted gene models and ESTs (Daphnia pulex v1.1, September 2006; http://www.jgi.doe.gov/ Daphnia and http://wFleaBase.org). Segment pairs with an E-value smaller than $10^{5}$ were selected and the corresponding scaffolds were manually curated with the help of Dappu v1.1 filtered gene models. Predicted gene structures were refined by comparison to Wnt genes from other species (Nematostella vectensis, Drosophila melanogaster, Tribolium castaneum, Apis mellifera, Homo sapiens, Mus musculus and Strongylocentrotus pupuratus) to identify the correct open reading frames. Partial cDNAs were cloned to confirm most intron-exon boundaries. Briefly, TRIzol (Invitrogen) was used to isolate RNA from Daphnia embryos of mixed stages. RNA was reverse transcribed using SuperScriptIII (Invitrogen) and RT-PCR was performed using primers specific to each predicted $W n t$ open reading frame. Sequence from each gene model was used to search the Daphnia assembly and confirm the presence of twelve Wnt gene sequences and the absence of any additional Wnt family members (Additional file 1). The synteny of Daphnia Wnt genes was inferred from their linkage on the same genomic scaffolds.

Gene models of nine Wnt genes from the tick Ixodes scapularis were retrieved from VectorBase [44] and
GenBank deposits (Additional file 1). A fragment of a tenth Ixodes Wnt gene was also identified through tblastn searches (Additional file 1).

Six Platynereis Wnt genes were isolated in a previous study [19]. Two more Wnt genes ( $P d-W n t 5$ and $P d$ Wnt8) were found in an EST collection [45]. To identify remaining Wnt orthologues a combination of more specific primers were used (Additional file 2). The accession numbers of all Wnt gene sequences used in this study are shown in Additional file 1.

\section{Phylogenetic analysis}

Two data sets were used for the analysis, the first set consisted of 93 amino acid sequences from arthropods, Platynereis and human (Additional file 3: Wnt sequence data set 1), and the larger second set included additional sequences from a nematode, cnidarian and three lophotrochozoans (Additional file 4: Wnt sequence data set 2 ). Sequences in both data sets were aligned using $T$ coffee [46] and hand-edited in SeaView [47] to remove poorly aligned amino acid positions (Additional files 3 and 4).

Initially, the best-scoring substitution model was determined among the amino acid models in RAxML [48] as WAG $+\mathrm{F}+\Gamma$ (WAG with empirical base frequencies and the $\Gamma$ model of rate heterogeneity; Whelan and Goldman [49]).

Bayesian phylogenetic analyses were performed with MrBayes [50]. The final topology was estimated using 13,000,000 iterations using 3250 burning cycles and sampling every 1000 iteration. Clade support was assessed with posterior probabilities computed with MrBayes and non-parametric bootstrapping implemented in RAxML [48] based on 1000 replicates.

\section{Animals}

Spiders (Achaearanea tepidariorum and Cupiennius salei) were obtained from laboratory stocks in Cologne and Göttingen [24,51]. Spider embryos were staged according to Akiyama-Oda and Oda [52]. General handling and staging of Glomeris is described in Janssen et al., [33]. Tribolium beetles (Ga-1 strain) were obtained from laboratory stocks at Kansas State University. Beetles were reared at $30^{\circ} \mathrm{C}$ in whole-wheat flour supplemented with $5 \%$ dried yeast. Platynereis larvae and juveniles were obtained from a breeding culture established in Gif-sur-Yvette according to the protocols of Fischer and Dorresteijn http://www.platynereis.de.

\section{Staining and microscopy}

Whole mount in situ hybridisation (WMISH) was performed for spiders as described in the published protocol for Cupiennius embryos [43]. For Glomeris, WMISH was performed as described in Prpic and Tautz [53] and 
Janssen et al. [32]. Both spider and Glomeris embryos were counterstained with Sytox Green or DAPI and images were captured with a Leica dissection microscope or a Zeiss Axioplan-2 microscope. For Tribolium and Platynereis, WMISH was performed as described previously [41,54-57]. All digital images have been subjected to adjustment of brightness, colour values and contrast using Adobe Photoshop CS3.

In Achaearanea and Cupiennius gene expression was investigated in stage 4 to stage 10 embryos, which represent germ disc embryos with radial symmetry (stages 4 to 6), and germ band embryos with axial symmetry (stages 7 to 10) and up to 7 opisthosomal segments $[52,58]$. In Glomeris, gene expression was investigated in stage 0 (blastoderm) to stage 6.1 embryos; see Janssen et al. [33] for a detailed description of staging. In Tribolium, gene expression was analysed in embryos at the fully extended germ band stage. In Platynereis, as in many other annelids, the elongation of the body axis continues during post-embryonic development as new segments are added from a sub-terminal SAZ [41]. We thus compared the expression of Wnt genes during trunk formation in both embryonic and post-embryonic development.

\section{Results}

\section{Phylogenetic analysis of Wnt protein sequences and} designation of Wnt gene subfamilies

Combining the findings of database searches, genome annotation, degenerate PCR and Wnt genes identified in previous studies (see Methods), we found a total of eleven Wnt genes in Achaearanea, (with WntA from Cupiennius representing a twelfth spider Wnt gene), seven in Glomeris, twelve in Daphnia, ten in Ixodes and twelve in Platynereis. These sequences were then aligned with the Wnt sequences of Acyrthosiphon pisum, Drosophila, Homo and Tribolium (Additional files 1 and 3). A further alignment was generated using a larger set of Wnt genes containing the Wnt sequences from Caenorhabditis, Capitella, Helobdella, Lottia and Nematostella in addition to the sequences used in the first set of Wnt genes (Additional files 1 and 4). We then carried out phylogenetic analyses using Maximum likelihood approaches (Wnt sequence sets 1 and 2) and additional Bayesian approaches (Wnt sequence set 1) (see Methods) (Figure 1 and Additional files 5, 6, 7).

Our phylogenetic analyses of both sets of Wnt sequences found good support for the thirteen metazoan Wnt gene subfamilies and twelve protostome Wnt subfamilies, which corroborates the findings of several previous studies (Figure 1 and Additional files 5, 6, 7) [17-19,21]. The phylogenetic assignment of Wnt genes from each organism to particular subfamilies is summarised in figure 2 .
Our results show that the common ancestor of the arthropods possessed members of all Wnt subfamilies with the exception of $W n t 3$, supporting the previous suggestion that $W n t 3$ was lost in the lineage leading to protostomes [17]. This is most strikingly evidenced by the identification of members of all the other twelve Wnt subfamilies in both Daphnia and Platynereis (Figures 1, 2 and Additional files 5, 6, 7).

Comparison of insects to other arthropods illustrates that the loss of Wnt genes appears to be more common among the insects, either through loss in the lineage leading to the insects, for example, Wnt2 and Wnt4, or losses in particular clades, for example, Wnt16 in holometabolous insects, Wnt11 in dipterans, and WntA in Drosophila (Figure 2). However there are probably also some cases of Wnt gene loss in non-insect arthropods, for example, Wnt10 may have been lost in chelicerates and myriapods (Figure 2), and we were unable to find a Wnt 2 orthologue in Ixodes. In addition, we cannot exclude that there has been more extensive loss of Wnt genes in Glomeris as an alternative explanation to limitations in screening using degenerate PCR in this species.

In contrast to the patterns of Wnt gene loss, the presence of duplicates of Wnt genes appears to be less frequent. While we found duplications of both $W n t 7$ and Wnt11 in Achaearanea, no other duplications have yet been found in any other arthropod (Figure 2). Furthermore, although duplications of Wnt5, Wnt11 and Wnt16 are found in other lophotrochozoans, we found only single copies of each Wnt gene in Platynereis (Figure 2) [17].

Several Drosophila and Caenorhabditis Wnt genes have previously been described as 'orphan' genes, however, our phylogenetic analysis allowed us to assign these genes to specific subfamilies. We found strong support that Drosophila WntD is the Drosophila orthologue of Wnt8 [19,59] (Figures 1, 2, and Additional file 5). Moreover, while the Caenorhabditis Wnt genes Cwn1, Cwn-2 and lin-44 were previously assigned to the Wnt4, Wnt5 and Wnt10 subfamilies respectively, the homology of mom-2 and egl-20 could not be determined [19]. Our analysis supports the previous assignments of Cwn-1, Cwn-2 and lin-44, and furthermore indicates that $m o m-2$ and $e g l-20$ are probably Wnt9 and Wnt16 orthologues respectively (Additional file 5).

\section{Synteny of Wnt genes}

Analysis of the arrangement of Wnt genes on the Daphnia genome scaffolds revealed two syntenic clusters of these genes: Wnt9-Wnt1-Wnt6-Wnt10 and Wnt5-Wnt7 (Additional file 8). This is consistent with similar $W n t$ clusters in other metazoans, including Nematostella, and therefore reflects an ancient arrangement of Wnt genes in animals $[17,60]$. Indeed Lottia gigantea and Daphnia 


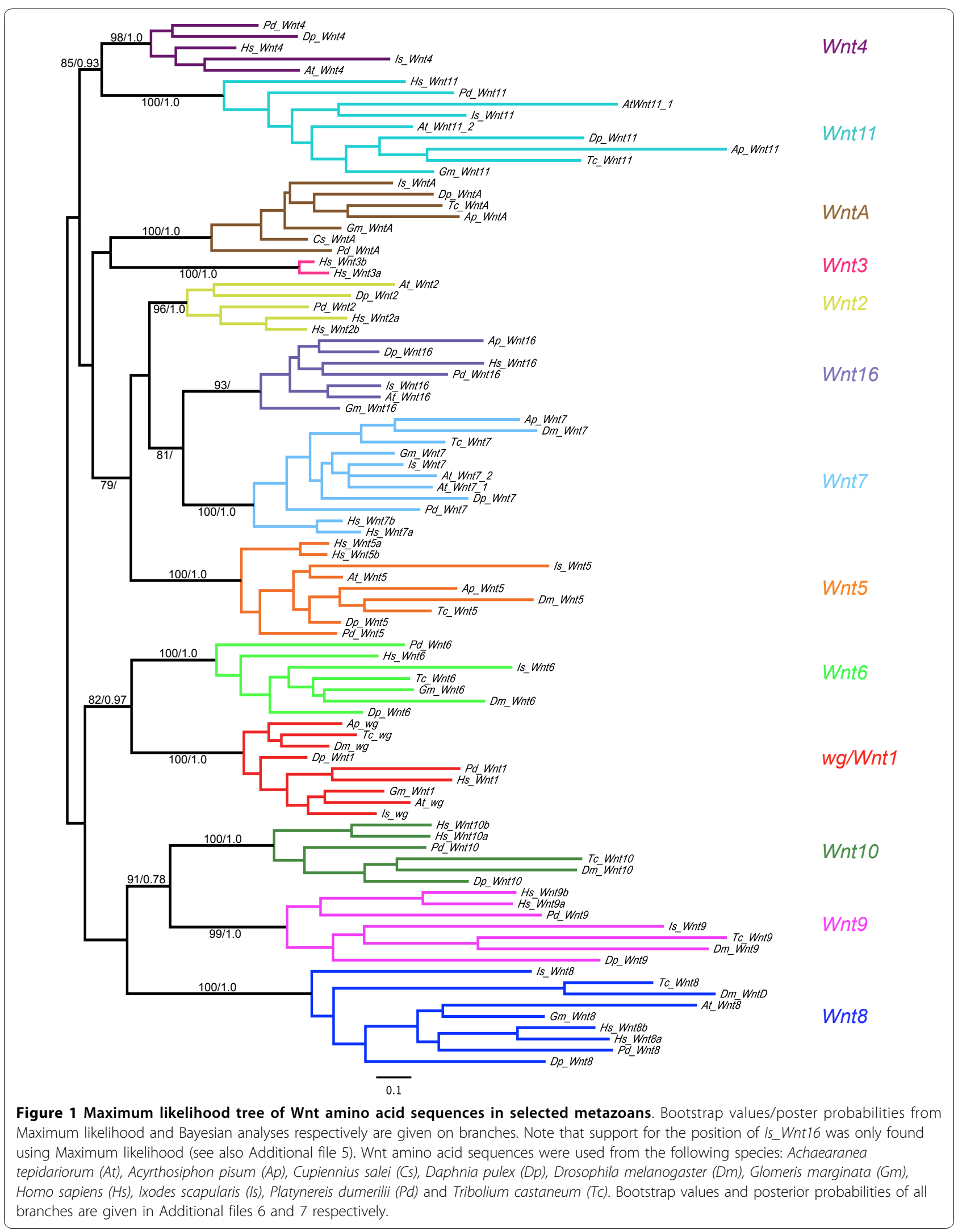




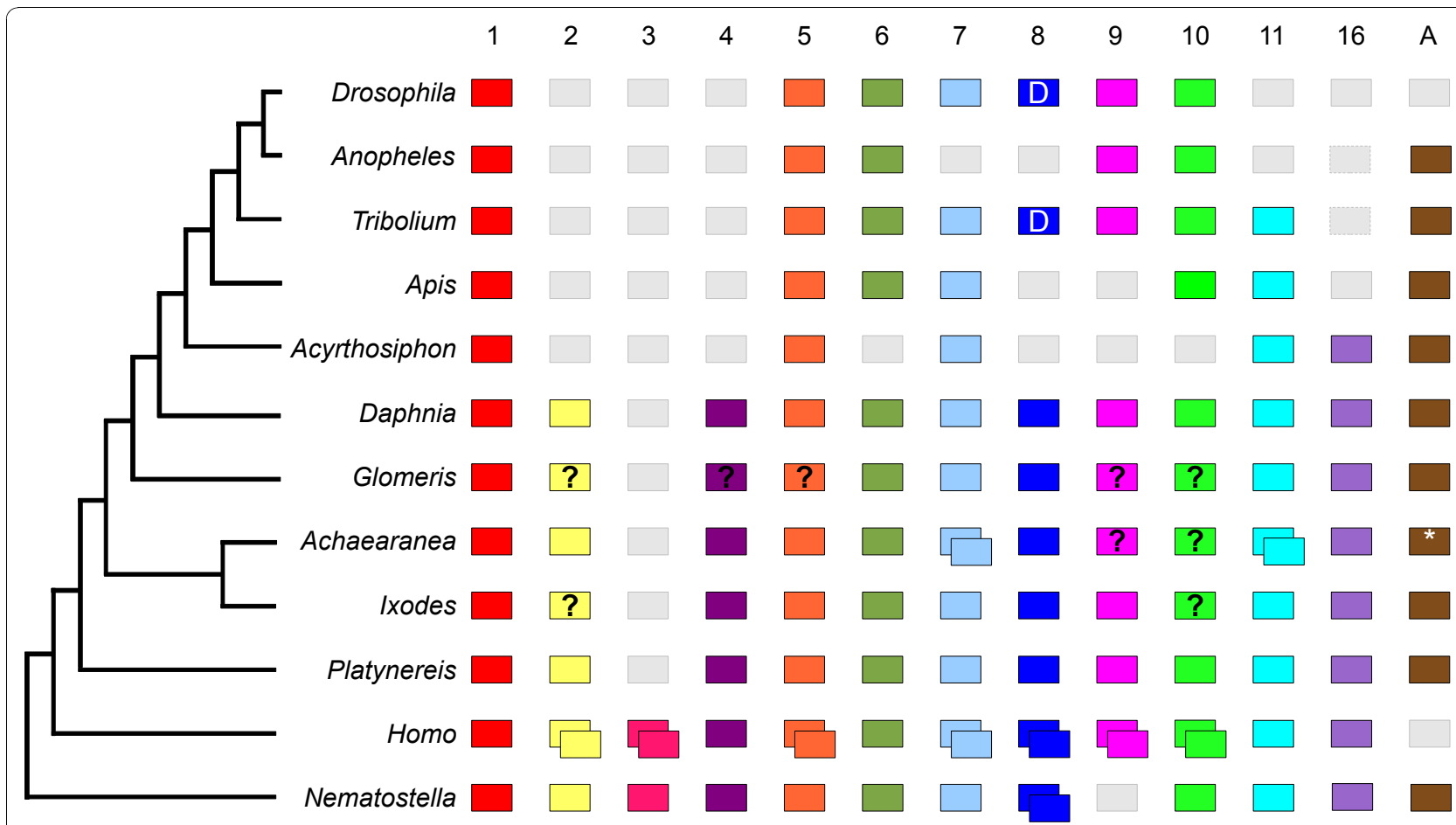

Figure 2 Metazoan Wht genes. The Wnt subfamilies ( 1 to 11, 16 and A) found in the various metazoans are represented by coloured boxes. Grey boxes indicate the loss of particular Wnt subfamilies and boxes with question marks indicate Wnts not found in some animals, but which cannot be definitively described as 'lost' because the relevant genomes have not been sequenced or require more comprehensive annotation. Duplicated Wnts are represented by two overlapping boxes. Note that Wnt8 is also called WntD in Drosophila and Tribolium. The phylogenetic relationships of the various animals is indicated by the tree on the left [14-16,21]. The asterisk indicates that for WntA an orthologue was isolated from another spider, Cupiennius. Note that the complete Achaearanea Wnt6 sequence was only identified subsequent to the phylogenetic analysis.

exhibit very similar organisation of these Wnt genes (Additional file 8). However, the precise organisation of these clusters can vary between lineages, for example, Wnt6 and Wnt9 are oriented differently in Drosophila and Daphnia (Additional file 8). Interestingly, these Wnt clusters may represent ancient duplications of Wnt genes; a hypothesis supported by the phylogenetic relationships of $w g$ and Wnt6, and Wnt9 and Wnt10 in our study (Figure 1 and Additional file 5) and several previous studies [17-19].

\section{Expression of Wnt genes}

To further compare the Wnt genes among arthropods and annelids and to investigate the possible developmental roles of these genes, we characterised the expression of these genes in Achaearanea, Glomeris, and Platynereis and further characterised Wnt genes with segmentally reiterated expression in Tribolium [14]. Note that the Drosophila Wnt gene names do not refer to homology with vertebrate Wnt subfamilies, but rather they were mostly named in the order they were discovered (e.g. DWnt2 is actually a Wnt7 orthologue not a $W n t 2$ orthologue). Therefore, below, we use the gene name with respect to its vertebrate orthologue and where appropriate give the Drosophila name in parenthesis, with the exception of $w g$ (also see Additional file 1).

\section{wg}

In Achaearanea, $w g$ is expressed in stripes in the $\mathrm{L} 1$ and L2 segments, but only during stage 8 , and such stripes are never observed in the other prosomal segments (Additional file 9: panel a). Subsequently, dots of $w g$ expression associated with the developing limb buds are observed in all prosomal segments (Figure 3a, and Additional file 9: panel b). In the opisthosoma, $A t-w g$ is only expressed in the dorsal cells of the $\mathrm{O} 2$ and $\mathrm{O} 3$ segments (Figure 3c, d, and Additional file 9: panel b), and is not observed in the SAZ at any stage (Figure $3 \mathrm{~b}$ ). Later in development, $A t$-wg expression continues in the prosomal appendages, and is also observed in opisthosomal limb buds, the labrum and the hindgut (Figure $3 \mathrm{~d}$, and Additional file 9: panel c).

In contrast, in a different spider, Cupiennius, $w g$ is expressed at the posterior of each parasegment and in the SAZ [30] consistent with classic roles in segment addition and boundary formation as described in other 


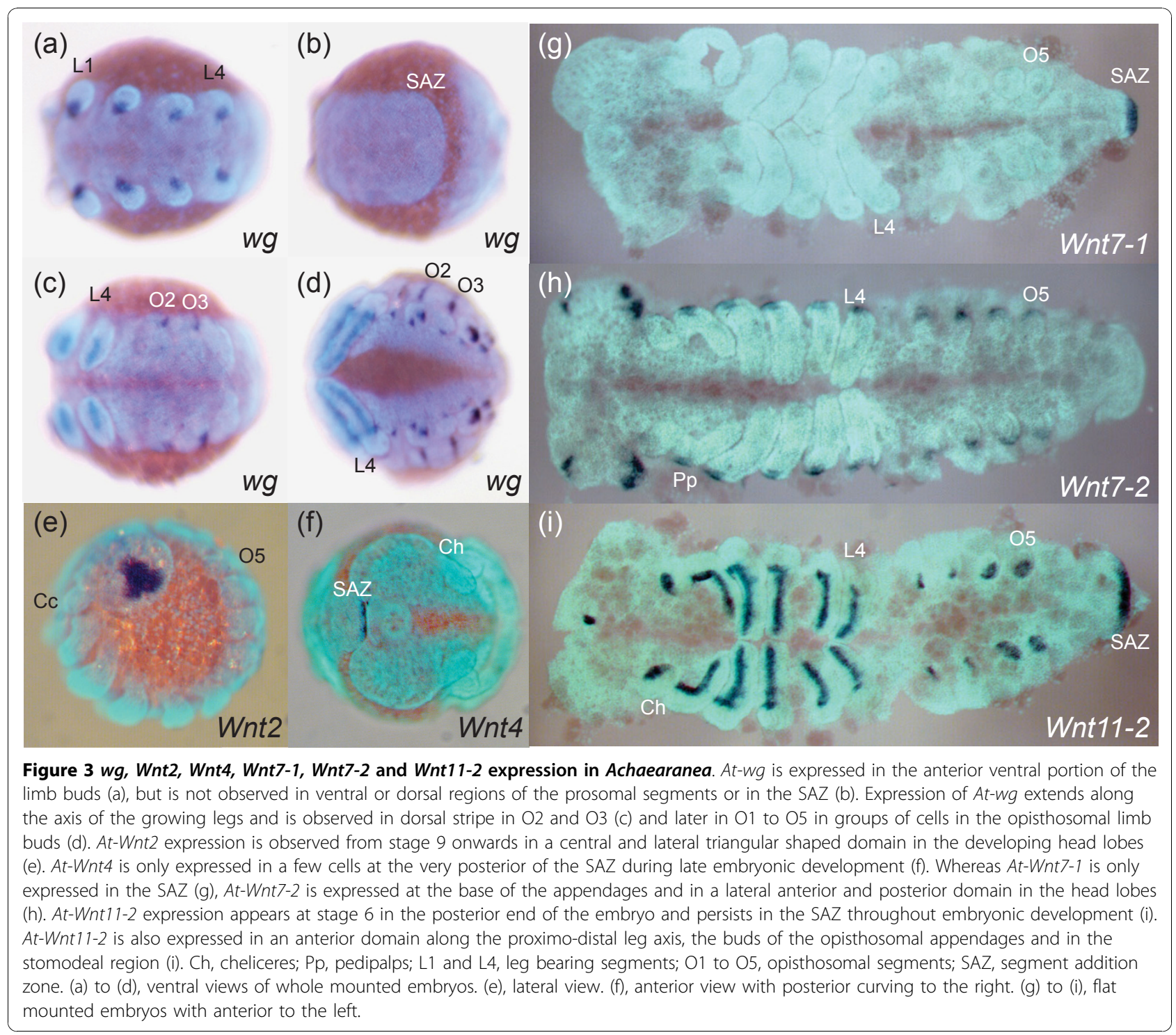

arthropods such as Tribolium (Figure 4a, b) $[3,33,34,61,62]$. Remarkably, this suggests that Achaearanea has either lost the expression and associated functions of $w g$ in most segments and the SAZ or there is an additional paralogous $w g$ gene in this spider not found in our PCR screen.

$w g$ expression in Platynereis was previously described in [35]. $w g$ is expressed at the posterior boundary of each segment both in the trochophore larva (Figure 5a, b) and during posterior growth (Figure 6a). During annelid posterior growth, $w g$ expression is also observed in the hindgut and in the posterior-most pygidial ectoderm (Figures 6b) [35].

\section{Wnt2}

It is likely that the Wnt2 subfamily was lost in the lineage leading to insects (Figure 2), and although we were unable to isolate an orthologue from Glomeris we assayed the expression of the Wnt2 genes from the spider Achaearanea and the annelid Platynereis.

In the spider Achaearanea, Wnt2 is first expressed relatively late in embryogenesis, in the ocular region of the developing cephalic lobes at stage 9, and this expression pattern persists into stage 10 (Figure 3e). We did not observe a distinct expression pattern for Wnt2 in Platynereis, possibly because of a low level of expression.

\section{Wnt4}

It is probable that the Wnt4 subfamily was also lost in the lineage leading to insects, but is present in other arthropods and lophotrochozoans (Figure 2). Analysis of Wnt4 expression in Achaearanea and Platynereis shows it is highly divergent between chelicerates and annelids. In Achaearanea, Wnt4 expression is restricted to only 

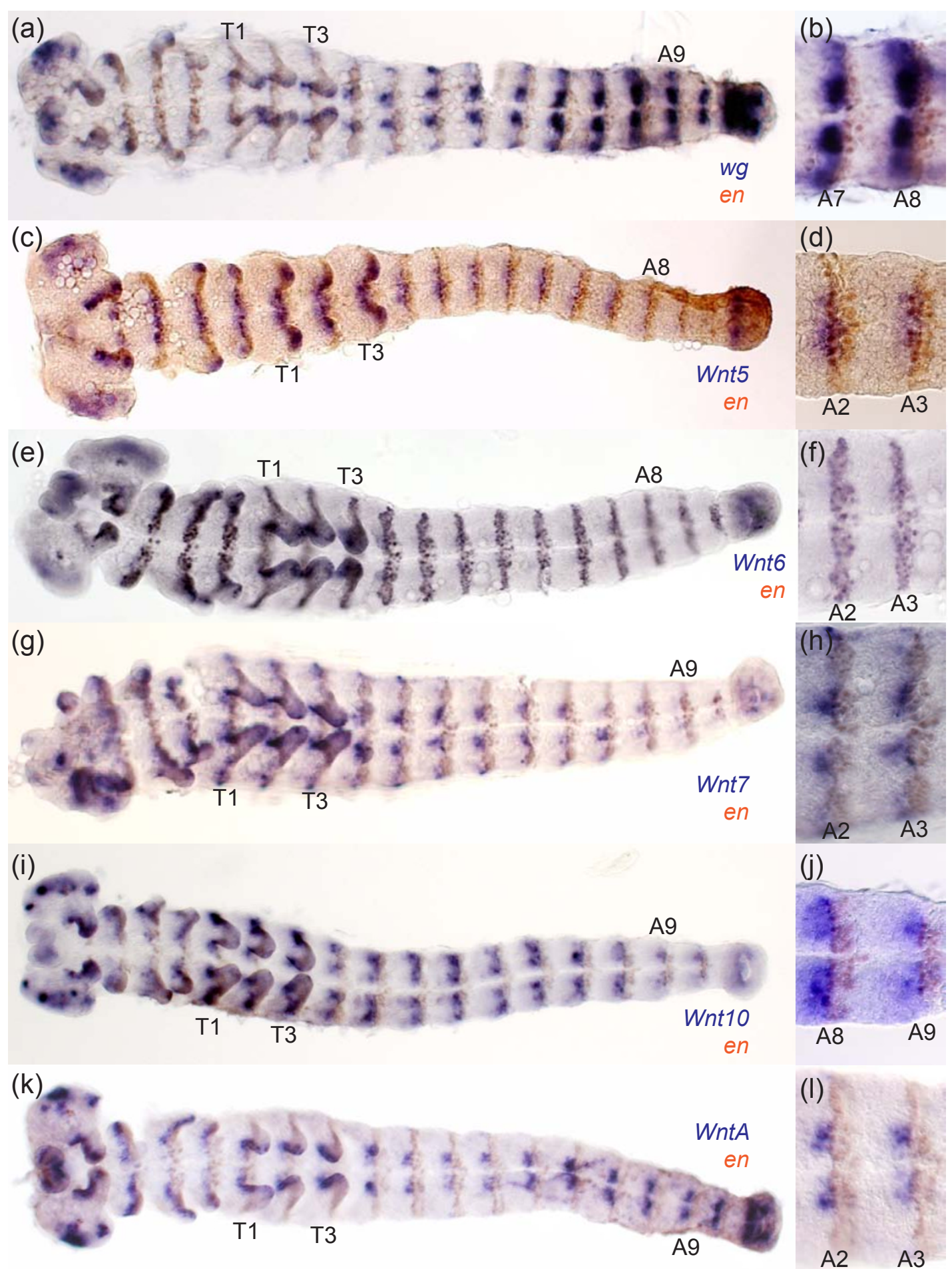

Figure 4 Expression of $\boldsymbol{w g}, W n t 5, W n t 6, W n t 7 W n t 10$ and $W n t A$ with respect to en in Tribolium. Germ band extended Tribolium embryos double stained for transcripts of en and wg (a), (b); Wnt5 (c), (d); Wnt6 (e), (f); Wnt7 (g), (h); Wnt10 (i), (j) and WntA (k), (l). High magnification images of segments are shown in (b), (d), (f), (h), (j) and (I). All embryos are shown with anterior to the left. thoracic (T1, T2) and abdominal (A2, A3, A8, A9) segments are indicated. 


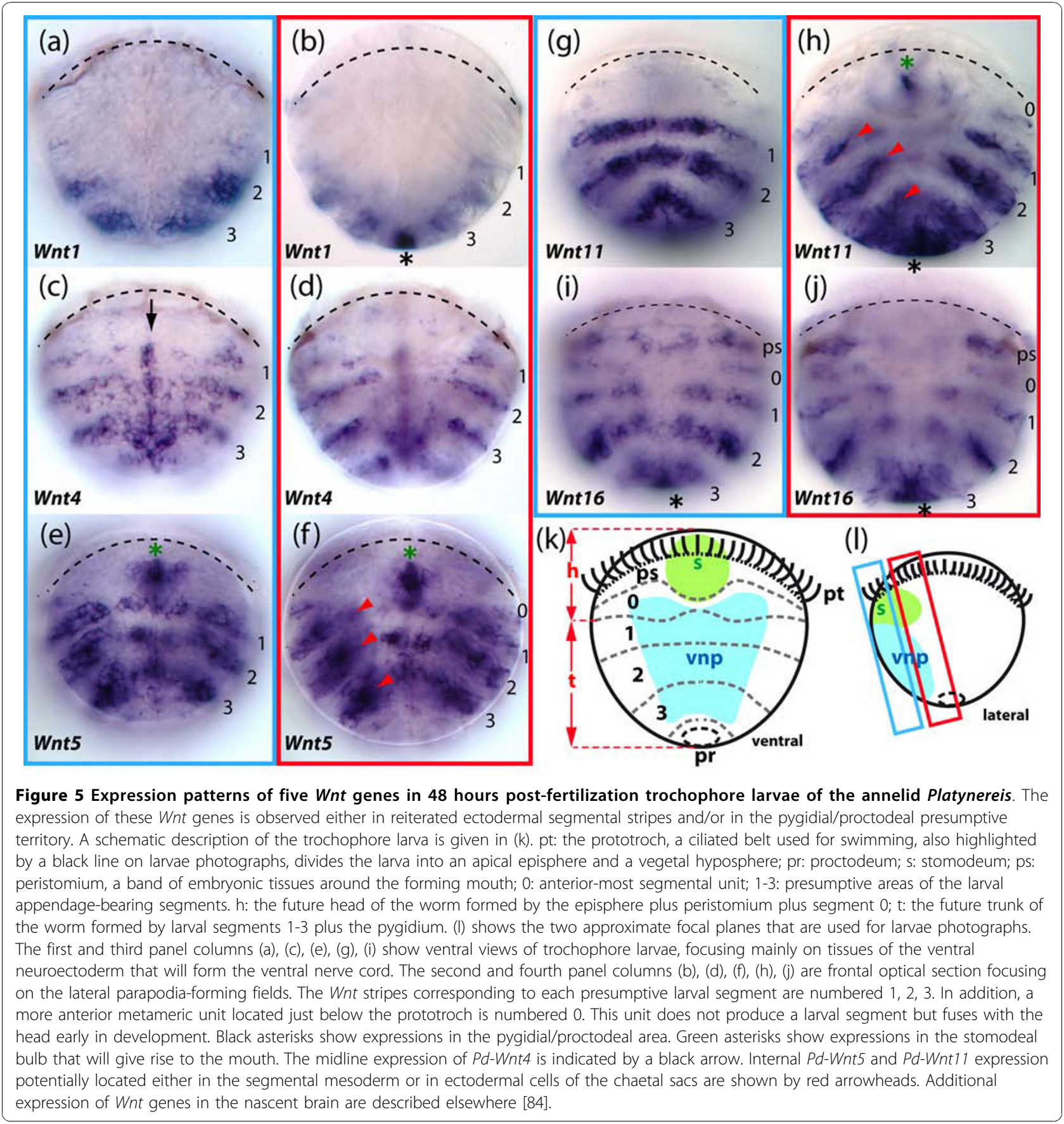

few cells at the very posterior of the germ band during the later stages of embryogenesis (Figure 3f). In contrast, in Platynereis, Wnt4 is expressed in stripes in the anterior part of each segment and could therefore be involved in defining segment boundaries (Figures 5c, d, 61). The stripes are limited to the dorsal and lateral parts of nascent embryonic and post-embryonic segments. Additionally, $P d-W n t 4$ is expressed in a longitudinal stripe along the ventral midline in forming segments as well as the SAZ and the ventral pygidial ectoderm (Figures 5c, d, 6l).

\section{Wnt5}

In Tribolium, Wnt5 is expressed in ventral stripes at the posterior of each parasegment and curiously in at least one row of cells in the anterior of each parasegment overlapping with en expression (Figure 4c, d). Tc-Wnt5 expression is also observed in the SAZ, distal tips of 

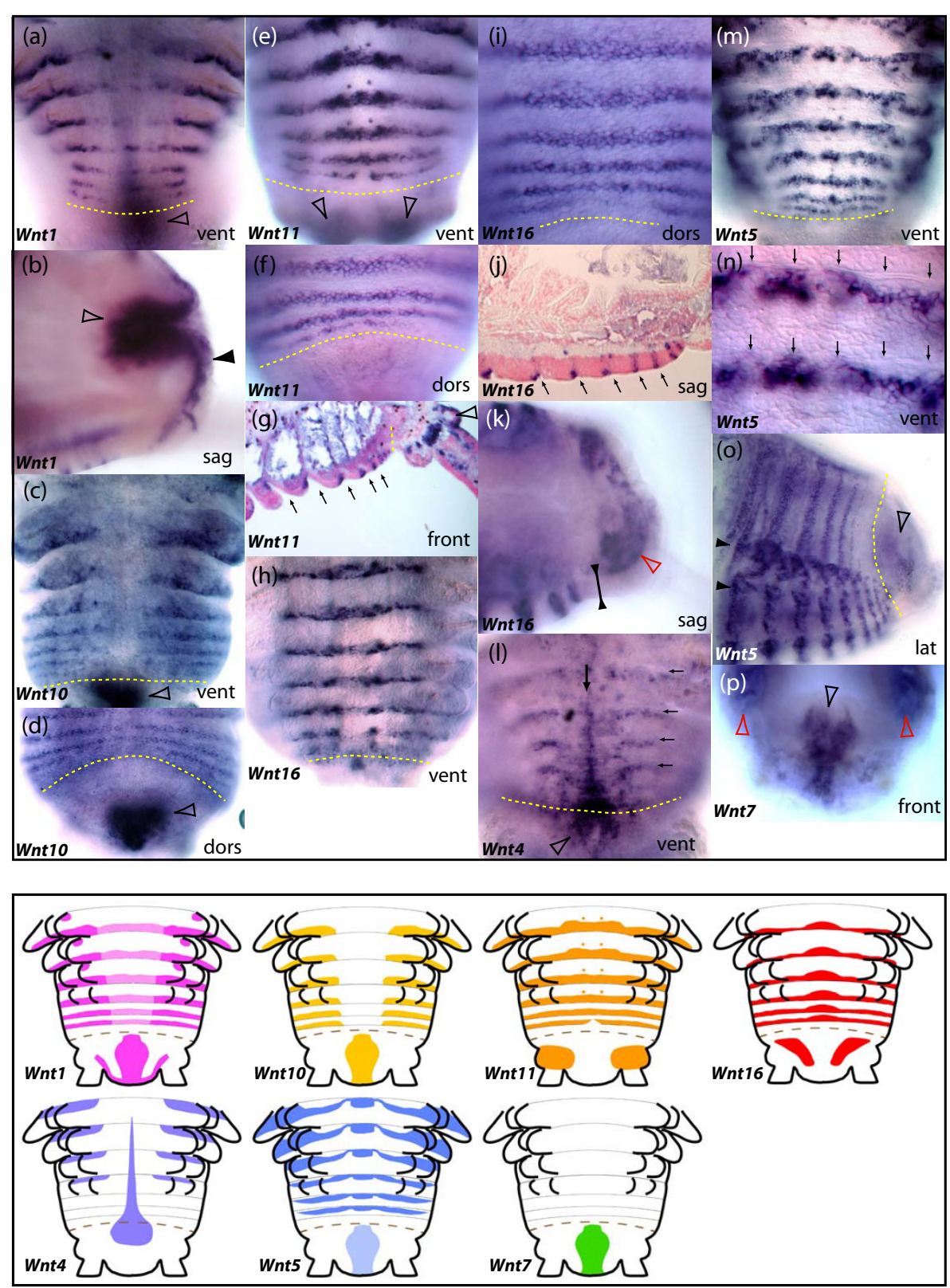

Figure 6 Expression patterns of seven Wnt genes during posterior segment addition in the annelid Platynereis. All panels show series of segments produced 8 days after caudal amputation and regeneration; vent, dors, lat: ventral, dorsal and lateral views respectively. Sag and front: sagittal and frontal sections (optical or tissue) respectively. The SAZ is highlighted with a yellow dashed line in all micrographs. The pygidium is located below or right of the SAZ line, depending on the view. In (g), (j), (I), (n), arrows indicate the position of segmental grooves. (a), (b) Expression of Wnt1 in the posterior part of forming segments and parapodia (a), in the hindgut (hollow arrowheads) and in the ectoderm of the pygidium (black arrowhead). (c), (d) Expression of Wnt10 in the posterior part of forming segments and parapodia, as well as in the hindgut (hollow arrowheads). (e)-(g) Expression of Wnt11 in the posterior part of forming segments and parapodia, in a pair of cells of the ganglia of the ventral nerve cord (black arrowhead) and in the ectoderm at the base of the pygidial cirri (hollow arrowheads). (g)-(k) Expression of Wnt16 in the posterior part of forming segments but not in parapodia. (k) Expression of Wnt16 in the mesoderm of the pygidium (red arrowhead) but not in the ectoderm (black arrowheads). (I) Expression of Wnt4 in the ventral midline of forming segments (black arrow), in the ventral part of the SAZ and pygidium (hollow arrowhead) and in the anterior part of forming segments. (m)-(o) Expression of Wnt5 in stripes in the anterior part of forming segments and in a complex pattern in the forming parapodia. (n) Is a close up view of $(\mathrm{m})$ at the level of the ventral ectoderm, showing the location of Wnt5 stripes posterior to the segmental grooves. (o) Shows the weaker dorsal stripes of Wnt5 that do not reach the dorsal midline, unlike Wnt10, Wnt11 and Wnt16. Black arrowheads show the forming parapodia. (p) Expression of Wnt7 in the hindgut (hollow black arrowhead) and broadly in the segmental mesoderm (red arrowheads). Patterns are recapitulated schematically in the lower part of the figure. All schemes are ventral views. A brown dashed line represent the SAZ. For the purpose of clarity, the expression of Wnt5 and Wnt7 in the mesoderm of forming segments has been omitted. 


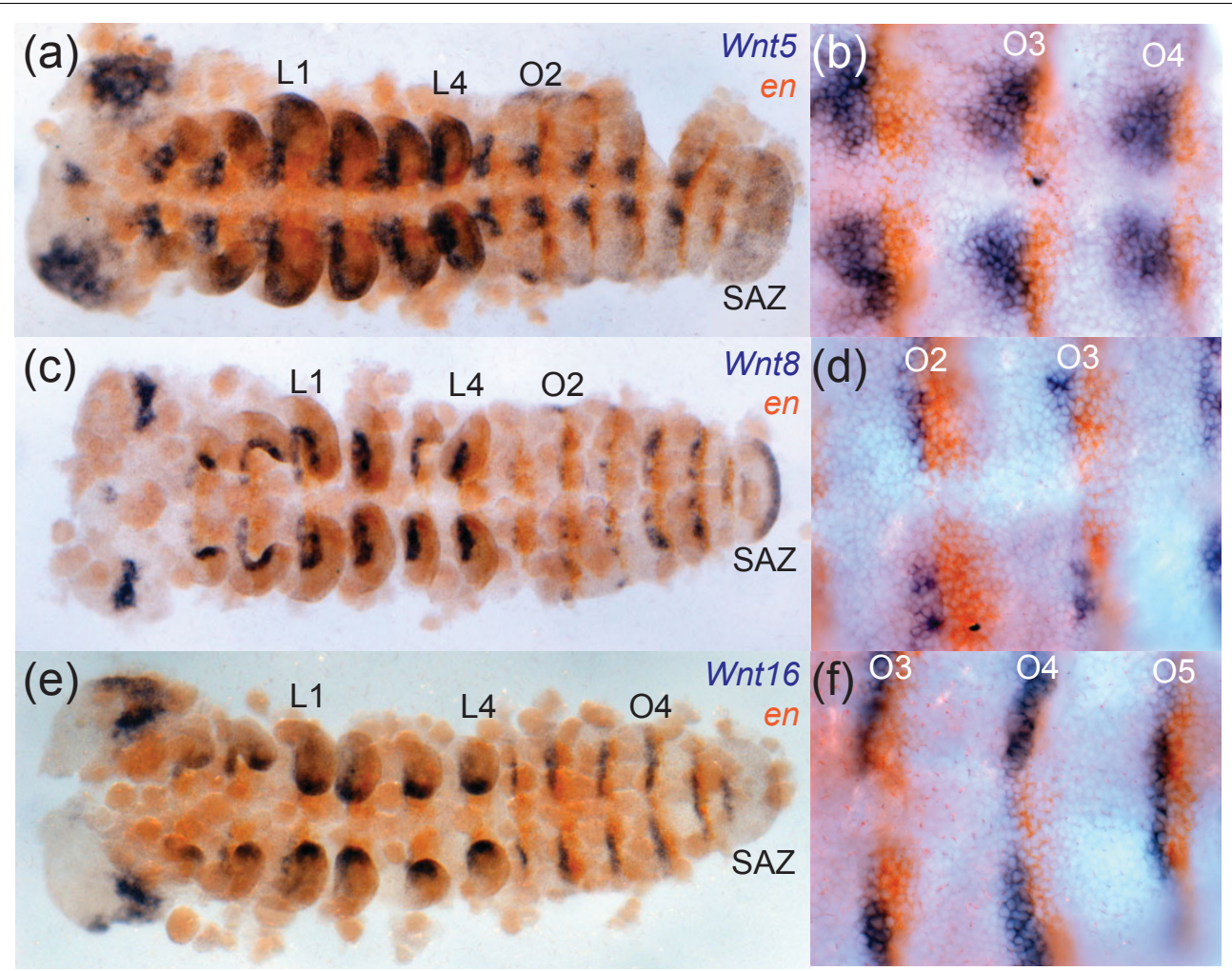

Figure 7 Expression of Wnt5, Wnt8 and Wnt16 in Achaearanea. At-Wnt5 is expressed segmentally in the developing neuroectoderm directly anterior to en (a), (b). At-Wnt5 expression can also be detected in the head lobes, the developing labrum, the developing heart, a ring like domain in the appendages and in the SAZ (a). At-Wnt8 is expressed segmentally and directly anterior to en expression (c), (d). At-Wnt8 is also expressed in the SAZ, the cephalic lobes, the developing stomodeum and the appendages. At-Wnt16 transcripts are also found in segmental strips directly anterior to en (e), (f), as well as in the tips of the legs and in a broad domain in the developing brain. At-Wnt16 expression is not observed in the SAZ (e). L1 and L4, leg bearing segments; $\mathrm{O} 1$ to O4, opisthosomal segments; SAZ, segment addition zone. All embryos are flat mounted with anterior to the left.

developing appendages, in the region of the labrum/ stomodeum, and the ocular region of the head lobes (Figure 4c) [14].

In Achaearanea, Wnt5 is first expressed in a broad anterior domain (Additional file 9: panel d), and subsequently, in the cephalic lobes, throughout the SAZ, and segmentally in the developing neuroectoderm on either side the ventral midline, juxtaposed to en expressing cells (Figure 7a, b). At-Wnt5 transcripts can also be detected in a medial ring in the appendages, the labrum and the heart (Figure 7a). Similar expression patterns have been described for Wnt5 in Cupiennius $[30,63]$.

In Platynereis, Wnt5 is also expressed in clear segmental stripes. However, in contrast to Wnt5 expression observed at the posterior region of parasegments in arthropods, $P d$-Wnt5 is only expressed in the anterior part of segments (Figures 5e, f, 6m-o, and Additional file 10: panel $\mathrm{f})$. These stripes encompass both the ectoderm and the underlying mesoderm (Figure 5f). $P d$ Wnt5 is also expressed weakly in the hindgut during posterior growth and in a complex pattern in forming appendages.

\section{Wnt6}

In Tribolium, Wnt6 is expressed in the developing brain, appendages, and in segmental stripes that overlap with en expressing cells (i.e. posterior to $w g$ expression) (Figure $4 \mathrm{e}, \mathrm{f}) . T c-W n t 6$ is also expressed in a sub-terminal region of the SAZ (Figure 4e) [14]. In Glomeris, Wnt6 is expressed in reiterated stripes in completed segments, directly anterior to en expression, and at later stages is observed in dorsal patches in each segment (Figure 8a, b) similar to Wnt6 expression in older Tribolium embryos. In addition, Gm-Wnt6 is expressed in specific domains in the developing brain, in and at the posterior of the germ band, including expression in the anal valves (Figure 8a). Diffuse expression of Gm-Wnt6 is also observed in the gut later in embryogenesis (not shown).

In Platynereis, Wnt6 is expressed in the mesoderm of trochophore larvae, and in the mesodermal layer of the 

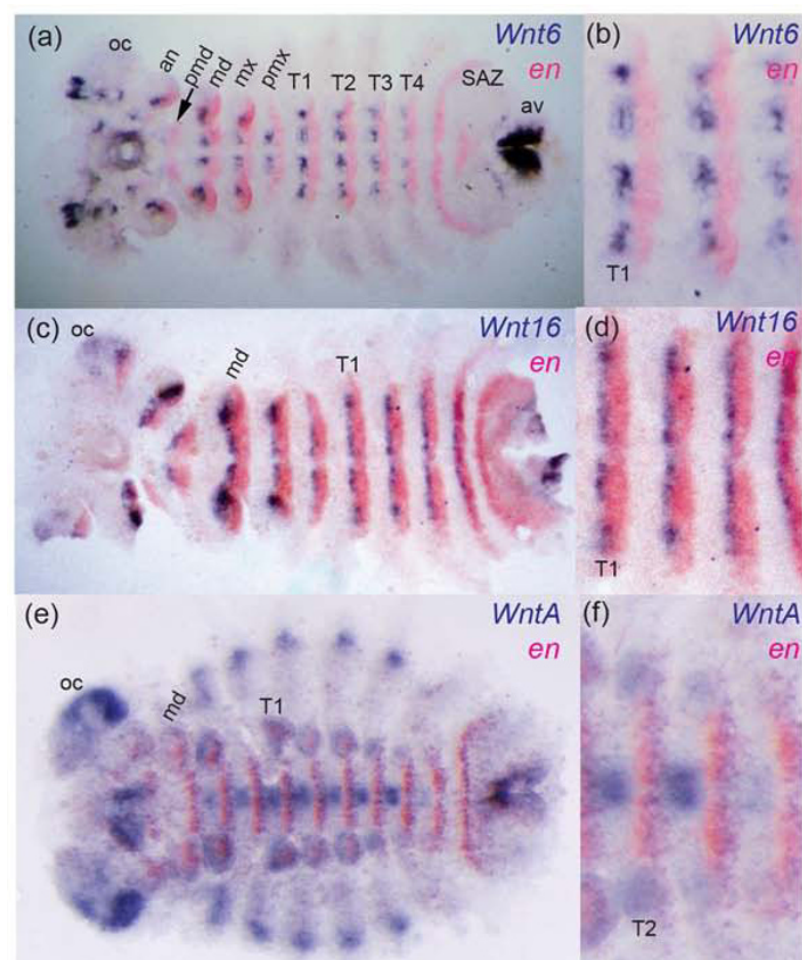

(f)

WntA

en
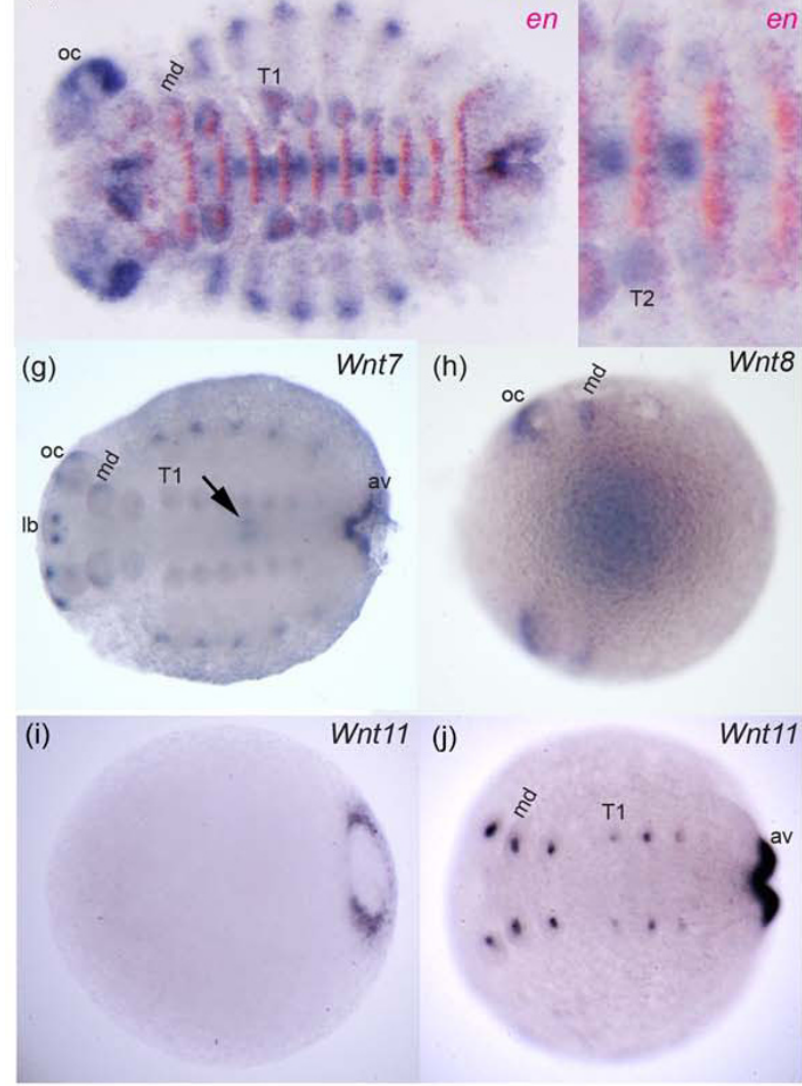

Figure 8 Expression of Wnt genes in Glomeris. Stage 3 embryo double stained for Wnt6 and en (a). Higher magnification of ventral trunk segments T1 to T3 of same embryo in (a) showing abutting expression of Wnt6 and en (b). Expression of Wnt16 and en in a stage 3 embryo (c). Higher magnification of ventral trunk segments T1 to T3 of same embryo in (c) showing abutting segmental expression of Wnt16 and en (d). Expression of WntA and en in a stage 5 embryo (e). Higher magnification of ventral trunk segments T1 to T4 of same embryo in (e) showing abutting segmental expression of WntA and en (f). Stage 5 embryo stained for Wnt7 (g). Arrow indicates expression in the midgut. Note that Gm-Wnt7 expression appears to be restricted to embryos older than approximately stage 3. Expression of Wnt8 in a stage 0.3 embryo (h). Faint expression of Gm-Wnt8 at the posterior is out of focus in this picture. Coloration in the middle of the embryo is in the yolk; this artificial staining appears when over-staining Glomeris embryos, which was necessary to detect specific Wnt8 transcripts. Note that Gm-Wnt8 expression appears to be restricted to embryos younger than approximately stage 1. Expression of Wnt11 in a stage 0.3 embryo (i) and a stage 3 embryo (j). Expression of Gm-Wnt11 is restricted to the anal valves (av) and the growing appendages (i), (j). Expression of Glomeris wg is described elsewhere $[32,33]$. All embryos are shown with anterior to the left. Embryos in (a) to (f) are flat mounted. Abbreviations: an, antennal segment; av, anal valve; lb, labrum; md, mandibulary segment; mx, maxillary segment; OC, optic lobes; pmd, pre-mandibulary segment; pmx, post-maxillary segment; T1-T4, trunk segments one to four. 
intestine in the growing juvenile (Additional file 10: panels a and g).

\section{Wnt7}

In Tribolium, Wnt7 is expressed segmentally in two clusters of cells either side of the ventral midline abutting en expressing cells, essentially in a similar pattern to $T c-w g$ (Figure $4 \mathrm{a}, \mathrm{b}, \mathrm{g}, \mathrm{h}$ ) [14]. Tc-Wnt7 is later expressed in the dorsal of the developing limbs and in the developing brain (Figure 4g) [14].

The two Achaearanea Wnt7 paralogues exhibit nonoverlapping expression patterns similar to subsets of $T c$ $W n t 7$ expression: $A t-W n t 7-1$ is expressed only in the SAZ (Figure $3 g$ ), and $A t-W n t 7-2$ is expressed in the proximal dorsal region of the developing appendages and in the developing brain (Figure $3 \mathrm{~h}$ ). However, neither of the spider Wnt7 genes or Glomeris Wnt7 is expressed in a segmental pattern like Tc-Wnt7. GmWnt7 is expressed in older embryos at the posterior of the germ band in the anal valves, the brain, the heart, the midgut, the labrum, the mandibles, and possibly also weakly in the other developing appendages (Figure 8g). In Platynereis, Wnt7 is expressed in the mesoderm of the larva (not shown) and later during juvenile growth (Figure 6p). Pd-Wnt7 is also strongly expressed in the hindgut (Figure 6p).

\section{Wnt8}

In Achaearanea embryos, Wnt8 is expressed in the posterior most cells of the SAZ, the cephalic lobes, the developing stomodeum, the appendages, and in ectodermal stripes anterior to $e n$ in each segment (Figure 7c, d) [24]. Although Wnt8 is also expressed in the SAZ of Tribolium embryos, it is not expressed segmentally in this beetle $[14,23]$.

In Glomeris, Wnt8 is expressed in two anterior domains and in the putative SAZ (albeit quite weakly), however, expression was only found in early embryos (Figure $8 \mathrm{~h}$ ) and no segmentally reiterated expression was observed.

Platynereis Wnt8 is expressed strongly in the future brain of the larva (Additional file 10: panel b). Faint ventral stripes are also detected in late stage trochophore larvae (Additional file 10: panel b), but no corresponding pattern is detected during posterior growth.

\section{Wnt9}

We were unable to isolate a Wnt9 gene from either spider species or Glomeris, but this may reflect a limitation of degenerate PCR rather than a loss in these lineages because a Wnt9 orthologue is found in the tick Ixodes (Figure 2). In Platynereis, Wnt9 is first expressed at the posterior pole in the trochophore larva (Additional file 10: panel c). During juvenile posterior growth, it is just observed in a few cells scattered in the gut endoderm (Additional file 10: panel h).

\section{Wnt10}

Again we were unable to isolate a Wnt10 gene from either Achaearanea or Glomeris and in addition no Wnt10 orthologue was found in the Ixodes gene models (Figure 2). In Tribolium, Wnt10 is expressed in a similar pattern to $w g$ in the cephalic lobes, appendages and at the posterior parasegmental boundaries abutting en expression (Figure 4i, j) [14]. Similar to $w g / W n t 1$ expression in Platynereis, Pd-Wnt10 is expressed at the posterior boundary of each segment and in the hindgut during posterior growth (Figure 6c, d). Surprisingly, we did not observe a similar expression pattern in the trochophore larva perhaps due to probe detection limitations. Instead, two pairs of cells were stained presumably in the anterior larval mesoderm (Additional file 10: panel $\mathrm{d}$ ).

\section{Wnt11}

There are two Wnt11 genes in Achaearanea. While we did not detect any embryonic expression of the Wnt11-1 paralogue, $A t$-Wnt11-2 is expressed in the SAZ starting at stage 6 (Additional file 9: panel e) and then throughout segmentation (Figure 3i). At-Wnt11-2 is also expressed in the developing appendages in an anterior domain along the proximo-distal axis of the prosomal appendages and in a distal domain in the buds of opisthosomal appendages (Figure 3i). In Glomeris, Wnt11 is first expressed at the posterior of the germ band (Figure $8 \mathrm{i}$ ), and later in the anal valves, and the tips of each appendage (Figure 8j). In the maxillae three spots of expression are also observed that resemble the expression of $w g$ in Glomeris (Figure 8j).

In Platynereis, Wnt11 is strongly expressed in segmental stripes in the posterior part of each segment in a similar position to $w g$ in the larva (Figure $5 \mathrm{~g}, \mathrm{~h}$ ) and during juvenile growth (Figure 6e-g). $P d-W n t 11$ is also expressed in the brain (not shown), the stomodeum and the presumptive pygidium (Figure $5 \mathrm{~h}$ ). During posterior growth, it is also strongly expressed posteriorly, but in the ectoderm covering the pygidium at the base of the tentacular cirri rather than in the hindgut like other Wnt genes (Figure 6e).

\section{Wnt16}

Investigation of Wnt16 expression in Achaearanea, Glomeris and Platynereis showed that in all three of these animals Wnt16 is expressed in segmental stripes directly anterior to en (Figures 5i, j, 6h-j, 7e, f, 8c, d). Thus like $w g$, Wnt16 might be involved in the generation of segmental and parasegmental boundaries in annelids and arthropods respectively (perhaps with the exception of 
holometabolous insects, see figure 2). In nascent segments of Glomeris and Achaearanea embryos, Wnt16 is observed in ventral restricted stripes (Figures 7e, f, 8c). However, in older segments $W n t 16$ is expressed in stripes either side of the ventral midline (Figures 7e, $\mathrm{f}$, 8c, d). Wnt16 expression is also observed in the cephalic lobes and the distal tips of the appendages in the spider and millipede (Figures 7e, 8c).

In Platynereis, Wnt16 is expressed in segmental stripes just at the posterior border of segments (Figure 5i, j, 6hk). Interestingly, the trochophore larvae show five stripes of Wnt16 of unequal strength, in addition to the three parapodia bearing larval trunk segments delineated by the other Wnt genes. Pd-Wnt16 is also expressed in the peristomium (the "ring" that carries the mouth just below the prototroch in annelids) and in a transient segmental anlage just posterior to it. Both segment-like structures fuse with the head at metamorphosis. During posterior growth, $P d$-Wnt16 is also expressed in the pygidium mesoderm, but not in the hindgut or pygidial ectoderm like other Wnt genes (Figure 6k).

\section{WntA}

Analysis of the expression of WntA orthologues in Tribolium, Cupiennius and Platynereis again revealed quite different patterns for this Wnt subfamily across protostomes. In Tribolium, WntA is expressed in the head lobes, appendages, SAZ and segmental stripes (Figure $4 \mathrm{k}, \mathrm{l})$ [14]. The segmental expression of WntA in Tribolium is again found anterior to $e n$ in a similar domain to $w g$ (Figure 4l). Glomeris WntA is expressed in clusters of cells in the ventral neuroectoderm posterior to en expressing cells, at the posterior end of the germ band (weakly) and developing heart (Figure 8e, f) [33]. Expression of WntA is also observed in the SAZ of the spider Cupiennius (Additional file 9: panel g), and although we also observed expression in a distal domain in the spinnerets and a lateral spot in the cheliceres, WntA is not expressed segmentally in this spider (Additional file 9: panels g-i). Thus WntA expression is rather different between mandibulates and chelicerates.

In Platynereis, $P d$-WntA is strongly expressed in the parapodial anlagen in larvae and during posterior growth (Additional file 10: panels e and i). $P d-W n t A$ expression is later observed at the distal extremities of growing parapodia (Additional file 10: panel i). A striped expression in the mesoderm during posterior growth has probably no connection to segment formation as high magnification shows that these stripes correspond to the walls of lateral blood vessel branching from the dorsal and ventral blood vessels (Additional file 10: panel j).

\section{Discussion}

Ancestral composition, conservation, loss and duplication of protostome Wnt genes

It has been shown that the thirteen subfamilies of Wnt genes found in metazoans appeared before the evolution of bilaterians, and that thirteen and twelve subfamilies are represented in extant deuterostomes and protostomes respectively [17-22] (Figure 2). Strikingly we have now found twelve Wnt subfamilies in both an arthropod, the crustacean Daphnia, and in the annelid Platynereis confirming that the common ancestor of protostomes contained all Wnt subfamilies except Wnt3. Furthermore, our study, the first broad survey of Wnt gene diversity across arthropods, shows that the common ancestors of arthropods and ecdysozoans also contained representatives of all twelve Wnt subfamilies found in protostomes (Figures 1, 2, and Additional file 5).

In insects there has been extensive loss of Wnt genes, for example, only seven and six Wnt genes are found in Drosophila and Acyrthosiphon respectively [14,16]. This reflects the absence of $W n t 2$ and Wnt4 in all insects and lineage specific patterns of loss such as Wnt11 in dipterans (Figure 2). Moreover, this suggests that while the loss of Wnt genes has been common in insects and the nematode Caenorhabditis, most ecdysozoans may actually have retained a larger repertoire of these genes (Figure 2). Similarly, the leech, Helobdella, also appears to have lost a number of Wnt genes with respect to other lophotrochozoans like Capitella [17] and Platynereis. However the reasons for retention of a large repertoire of Wnt genes in some lineages and extensive loss in others is currently unknown.

Curiously duplications of individual $W n t$ genes (i.e. apart from those generated by whole genome duplications in deuterostomes) are rather rare (Figure 2). The reason for this could be that the concentration of individual Wnt ligands is important for the overall combinatorial output of Wnt signalling in particular tissues (see below). Indeed, in animals with Wnt duplications, the paralogues appear to have been subject to subfunctionalisation, as evidenced by distinct expression patterns of the Wnt7 and Wnt11 paralogues in the spider, and duplicated Wnt genes in lophotrochozoans [17]. Our data also support previous phylogenetic studies of Wnt genes suggesting ancient duplications may have given rise to clusters of Wnt genes, such as the Wnt9-wgWnt6-Wnt10 cluster found in Daphnia and other metazoans (Additional files 5 and 8).

\section{Combinatorial action of Wnts}

Our present study of Wnt gene expression in a range of arthropods and an annelid, and previous studies in 


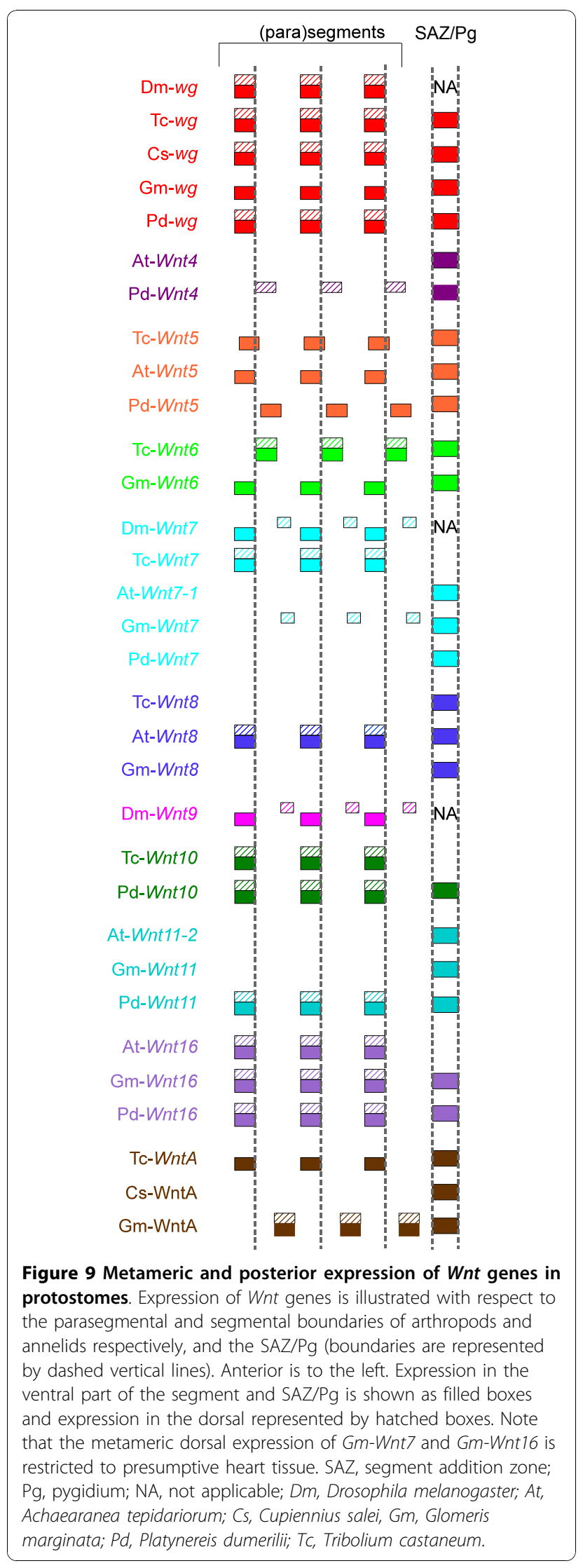

other metazoans $[14,17,18,21,64,65]$, show that numerous Wht genes are often expressed in the same cells or tissues; for example, various Wnt genes are expressed in the SAZ and at the same position within segments (Figure 9). Does this imply that Wnt ligands are essentially redundant? The lack of obvious phenotypic effects associated with the loss of expression of some $W n t$ genes in particular tissues suggests that they may be functionally interchangeable in certain contexts [e.g. $[23,66]]$. However, there are also several arguments against the general functional redundancy of these ligands. First, the fact that twelve or thirteen Wnt genes are retained in many animals argues against redundancy. Second, since Wnt ligands diffuse from source cells and thus can act on a range of different target cells, expression of multiple Wnts in the same cell does not necessarily mean they have the same function. Third, studies directly comparing the function of different Wnts have provided direct experimental evidence that these ligands are functionally distinct. In Drosophila wg and Wnt9 (DWnt4) have similar expression in segmental stripes, but they play different roles in ectodermal patterning [5,67], while overexpression of the other five Drosophila Wnt genes has no affect on cuticular patterns $[64,68]$. Furthermore, Llimargas and Lawrence [64] found that $w g$ and $W n t 7$ (DWnt2) act together during Drosophila tracheal development, but none of the five other Drosophila Wnts could perform the same roles. These results, as well as those of studies in Caenorhabditis [e.g. [65,66]], reflect increasing evidence that Wnt signalling is more complex than simple linear signalling pathways, and that Wnt ligands expressed in similar patterns may work agonistically and antagonistically to fine tune cellular responses [42]. Indeed, it is perhaps even more realistic to think of an overall Wnt ligand landscape or code rather than the function of individual Wnts [69].

The specificity of Wnt signalling is also facilitated by the great complexity of transduction mechanisms employed [42]. Wnt ligands are capable of binding to several different receptors, including 7-pass Frizzled receptors and the receptor tyrosine kinases Ryk and Ror, which in turn are capable of activating several crosstalking cytoplasmic pathways. It has been proposed that these transduction mechanisms allow a combinatorial action of Wnt ligands in particular tissues [42]. Interestingly, however, this also opens the possibility that a given cellular response might be achieved with several different Wnt ligand combinations. Therefore, the expression of alternative Wnt combinations in a given tissue in different taxa could still generate the same intracellular signalling outcome. This may partly explain the diversification Wnt ligand gene expression across metazoans. 


\section{Wnts and segmentation in protostomes}

Our analysis allows the first broad comparison of Wnt expression patterns across the arthropods, and our characterisation of Wnt expression in an annelid extends this comparison to other segmented protostomes.

Arguably, one of the most interesting observations emerging from this comparison is the high proportion of Wht genes expressed in segmental stripes reminiscent of segment polarity gene expression in Drosophila (Figure 9). In fact, no less than six Wnt genes show this kind of pattern in Platynereis and Tribolium, and at least five in Glomeris and four in Achaearanea (Figure 9). It is particularly striking that eleven out of twelve protostome Wnt genes (the exception being Wnt2) exhibit a striped pattern in at least one species, and no less than nine (Wnt11 and Wnt4 are the exceptions) in at least one arthropod (Figure 9). Generally, these stripes appear before the morphological appearance of segments, suggesting that some of these genes may play roles in segment formation, although others may only be involved in the ontogenesis of segmental organs rather than segmental patterning. The last common ancestor of all arthropods was undoubtedly a metameric animal, and our study suggests that a number of Wnt genes probably played a role in the patterning of its segments. However, only $w g$ is expressed in similar stripes across all arthropod species considered here, and even the function of this gene may have changed somewhat in Achaearanea. Therefore, some Wnt genes have lost their segmental expression in some lineages, and indeed, Wnt16 was lost altogether in holometabolous insects (Figure 2). Conversely, some Wnt genes may have evolved segmental patterning functions, for example, Wnt7 in Tribolium.

Experimental approaches have also revealed differences among Wnt genes with respect to their role in segmental patterning. In Drosophila, only wg and Wnt9 (DWnt4) appear to regulate the establishment of the metameric pattern $[5,7,64,68,70]$. In Tribolium, while $w g$ RNAi produces segmentation defects [23], RNAi against other segmentally expressed $W n t$ genes did not affect segmentation. Clearly functional data on the other $W n t$ genes in arthropods, particularly non-insect arthropods, is required to investigate the roles of these genes in segmental patterning further.

Despite differences in the expression and probably the function of Wnt genes across taxa, there are nevertheless some noticeable similarities: Wnt5 is expressed in ventral stripes in Tribolium, Achaearanea and Platynereis; Wnt16 is expressed in reiterated stripes in Achaearanea, Glomeris and Platynereis; Wnt10 forms stripes in Tribolium and Platynereis (Figure 9). Furthermore, with a few exceptions, segmental expression of $W n t$ genes nearly always anteriorly abuts en expression in arthropods (Figure 9). Together with the fact that no Wnt gene demarcates the segmental boundary in arthropods (with the possible exception of Tribolium Wnt6), this vindicates the view that parasegment boundaries are the essential organizers of segmental patterning in these animals $[30,31]$.

It was previously proposed that the ancestral protostome was an annelid-like segmented worm, and that arthropod cuticular segmentation evolved out of frame with the ancestral segmentation [71]. This is supported by en, wg [35] and hedgehog [36] expression patterns in Platynereis. In this view, arthropod parasegments are an embryonic recapitulation of ancestral segmentation. In Platynereis, although incomplete stripes of Wnt4 and $W n t 5$ are found in the anterior region of segments, $w g$, Wnt10, Wnt11 and Wnt16 are all expressed in circular stripes at the posterior segmental boundaries, anterior to en (Figure 9), thus supporting the hypothesis that arthropod parasegments and annelid segments are homologous. It is noteworthy, however, that the analysis of the expression patterns of a complete set of Wnt genes in another annelid, the leech Helobdella, led the authors of this study to very different interpretations [17]. In the leech, the duplicated genes Wnt11a, Wnt11c, Wnt16a and Wnt16b also give striped segmental patterns but only in the late germ band stage well after the segmental pattern is already laid down, whereas in Capitella, Wnt5, Wnt11 and Wnt16 are not expressed in ectodermal stripes but rather in segmentally iterated patterns in the mesoderm [17]. Only Capitella Wnt11 is expressed transiently in the ectoderm of the SAZ. These discrepancies show that the actual role of Wnt signalling in segment formation will have to be tested in detail in non-insect arthropod and annelid models before reaching conclusions on its evolution.

\section{Wnt signalling and posterior development}

Drosophila undergoes a long germ band mode of development, where all segments are formed simultaneously. In contrast most insects and other arthropods develop through variations of the short germ band mode, which is more ancestral. In the short germ band mode of development, only the anterior-most segments are initially specified and subsequently the posterior segments are added sequentially from unsegmented posterior tissue, which is often called a posterior growth zone [72,73]. However, even within arthropods, the term "growth zone" encompasses a diversity of tissue types that use different combinations of cell proliferation, movement and differentiation to generate new segments [40]. Therefore, the 'growth zone' may be more appropriately named a segment addition zone (SAZ) because sequential addition of segments is truly the key common process involved $[31,40,41]$. Despite differences in the 
process of segment addition among arthropods, it has also been argued that this is an ancestral character of bilaterians [41].

A large proportion of Wnt genes in Tribolium, Achaearanea and Glomeris embryos are expressed in the SAZ (Figure 9). The crucial role played by Wnt signalling during segment addition has been functionally demonstrated in a few arthropods. Wnt8 knockdown in both Tribolium and in Achaearanea resulted in a posterior truncation of the body [23,24]. A similar phenotype is obtained in Oncopeltus with $w g$ RNAi [25], but not in Tribolium [23] or Gryllus [74], despite expression of $w g$ in the SAZ of this beetle. This suggests that the respective roles of Wnt ligands during segment addition have evolved differentially among arthropod lineages, and is consistent with differences in the expression of Wnt genes in this region (Figure 9).

Axis truncations produced by depletions of armadillo/ $\beta$-catenin, pangolin/TCF and arrow/LRP5/6 in Gryllus, Tribolium and Oncopeltus $[23,25,74,75]$ further evidence the crucial role played by the $\beta$-catenin pathway in segment addition. Nevertheless, given the multiplicity of ligands involved, it will be important to investigate whether posterior addition of segments in arthropods is regulated by Wnt ligands through combinatorial transduction pathways [42].

Analysis of posterior expression of Wnt genes in the annelid Platynereis brings some valuable insight to understanding segment addition in protostomes. No less than six Wnt ligands are expressed in the terminal region of the annelid body, the pygidium, during axis elongation. However the annelid SAZ is located anterior to the pygidium and is represented by a thin ring of cells in which even-skipped and caudal (cad) are involved in regulating the synchronous mitotic cycles that produce new segments [41]. The posterior expression domains of Platynereis wg, Wnt5, Wnt7, Wnt10, Wnt11 and Wnt16 cannot completely be superimposed because they cover the hindgut, the external pygidial ectoderm, and the pygidium mesoderm. However none of these Platynereis Wnt genes is actually expressed in the SAZ sensu stricto, suggesting that they act from a posterior signalling centre located in the mitotically quiescent pygidium and separate from the proliferating cells that are the source of the new segments [41].

In the short germ band arthropods considered in this work, the detailed organization of the SAZ is largely unknown and therefore it is not known if there is a separate segment founder cell zone and putative signalling centre that differentially express Wnt genes. Clearly some arthropod Wnt genes are expressed in the proctodeum towards the end of embryogenesis, and thus in a location homologous to the annelid hindgut. Interestingly, the posterior expression of $w g$ in an arthropod with anamorphic development (segments are added during larval development), the crustacean Triops, shows two separate domains: a complete ring near or in the SAZ and the hindgut [62].

It has been shown that knockdown of the posteriorly expressed $W n t 8$ in a spider perturbs the posterior expression of cad and Delta/Notch pathway components [24]. Given similar observations in several vertebrates [76-79], a Wnt signalling centre acting upstream of cad and the Delta/Notch pathway may have regulated posterior development in the last common ancestor of bilaterian animals (Urbilateria) [80,81]. This interpretation is further strengthened by the arthropod expression data in our study. Moreover, we also found evidence for a posterior Wnt signalling centre in a distantly related protostome group, the annelids, in which cad and Delta/Notch are also involved in posterior addition $[41,82,83]$. However, the evolution of posterior Wnt signalling has likely been complex in bilaterians, for example, Wnt8 is not expressed at this location in annelids and therefore its role must be played by one or several other Wnts ligands in these animals.

\section{Conclusions}

We have found evidence that combinations of many Wnt genes probably regulate segment addition and patterning across protostomes. However further functional studies in a range of protostomes are required to investigate the precise roles of these ligands during these important developmental processes. As well as giving greater insights into the complexities of Wnt signalling, such analyses will also allow questions regarding the evolution of segmentation $[37,38]$ to be addressed further.

\section{Additional material}

Additional file 1: Table of species and Wnt genes used in this study. Additional file 2: Table of degenerate primer sequences.

Additional file 3: Alignment of $\mathbf{9 3} \mathbf{W n t}$ amino acid sequences from Achaearanea, Acyrthosiphon. Cupiennius, Daphnia, Drosophila, Glomeris, Homo, Ixodes, Platynereis and Tribolium.

Additional file 4: Alignment of 147 Wnt amino acid sequences from Achaearanea, Acyrthosiphon, Caenorhabditis, Capitella, Cupiennius, Daphnia, Drosophila, Glomeris, Helobdella, Homo, Ixodes, Lottia, Nematostella, Platynereis and Tribolium.

Additional file 5: Maximum likelihood tree of metazoan Wnt amino acid sequences from set 2 . Bootstrap values from Maximum likelihood analysis are given on branches. Wnt amino acid sequences were used from the following species: Achaearanea tepidariorum (At), Acyrthosiphon pisum (Ap), Caenorhabditis elegans (Ce), Capitella teleta (Ct), Cupiennius salei (Cs), Daphnia pulex (Dp), Drosophila melanogaster (Dm), Glomeris marginata $(\mathrm{Gm})$, Helobdella robusta $(\mathrm{Hr})$, Homo sapiens $(\mathrm{Hs})$, Ixodes scapularis (Is), Lottia gigantea (Lg), Nematostella vectensis (Nv), Platynereis dumerilii $(P d)$ and Tribolium castaneum (TC).

Additional file 6: Maximum likelihood tree of Wnt amino acid sequences from set 1 . Bootstrap values are given on branches. Wnt 
amino acid sequences were used from the following species: Achaearanea tepidariorum (At), Acyrthosiphon pisum (Ap), Cupiennius salei (Cs), Daphnia pulex (Dp), Drosophila melanogaster (Dm), Glomeris marginata $(\mathrm{Gm})$, Homo sapiens (Hs), Ixodes scapularis (Is), Platynereis dumerilii (Pd) and Tribolium castaneum (TC).

Additional file 7: Bayesian tree of Wnt amino acid sequences from set 1. Posterior probabilities are given on branches. Wnt amino acid sequences were used from the following species: Achaearanea tepidariorum (At), Acyrthosiphon pisum (Ap), Cupiennius salei (Cs), Daphnia pulex (Dp), Drosophila melanogaster (Dm), Glomeris marginata $(\mathrm{Gm})$, Homo sapiens (Hs), Ixodes scapularis (Is), Platynereis dumerilii (Pd) and Tribolium castaneum (TC).

Additional file 8: Synteny of Wnt genes in metazoans. Position and orientation of syntenic Wnt genes in Drosophila melanogaster, Tribolium castaneum, Apis mellifera, Daphnia pulex, Lottia gigantea and Nematostella vectensis. The sizes of the clusters are not drawn to scale. Note that Wnt5 and Wnt7 gene are found in Drosophila, Tribolium and Apis but are not clustered in these species.

\section{Additional file 9: $w g, W n t 5, W n t 11$ and Wnt16 expression in} Achaearanea, and WntA expression in Cupiennius. At-wg expression is first detected at stripes in L1 and L2 (a). By stage 9, At-wg is expressed in anteroventral regions of the prosomal limb buds and dots in the dorsal of $\mathrm{O} 2$ and $\mathrm{O} 3$, but no expression is seen in the other opisthosomal segments or in the SAZ (b). Later at stage 10, At-wg is expressed as stripes in $\mathrm{O} 2$ and $\mathrm{O} 3$ and expression is also observed in the labrum and the hindgut (c). At-Wnt5 expression is first observed in an anterior stripe at stage 5 that broadens during stage 6 (d). At-Wnt11-2 is first expressed at the posterior pole of the embryo during stage 6 (e). Similar to AtWnt5, At-Wnt16 expression is observed as a broad anterior stripe at stage 6 (f). Strong expression of Cs-WntA is visible in the SAZ (g), $\left(g^{\prime}\right)$. Weaker expression of Cs-WntA is also detectable at the distal ends of the spinnerets (h), ( $h$ ') and in two small spots in the cheliceres (i), (i') indicated by arrows. Lateral views are shown in (a), (b), (g) and $\left(g^{\prime}\right)$, ventral views with posterior wrapping to the right in (c), (d) and (f), posterior view with dorsal up in (e), ventral views with posterior to the right in ( $h$ ) and ( $\left.h^{\prime}\right)$, and anterior views with posterior to the right in (i) and (i'). Brightfield and DAPI counterstained images of the same embryos are shown in (g), (h), (i) and $\left(g^{\prime}\right),\left(h^{\prime}\right),\left(i^{\prime}\right)$ respectively. Ch, cheliceres; Lb, labrum; L1 and L4, leg bearing segments; $\mathrm{O} 1$ to 05 , opisthosomal segments; SAZ, segment addition zone.

\section{Additional file 10: Additional expression patterns of Wnt ligand} genes in the annelid Platynereis. (a)-(e) ventral views of $48 \mathrm{hpf}$ trochophores. The black dashed line is the prototroch. Red arrowheads: Broad Pd-Wnt6 expression in the mesodermal bands (a) and in few cells of the anterior mesoderm for Pd-Wnt10 (d); Black hollow arrowhead: PdWnt9 expression in the proctodeum; Black asterisk: $P d-W n t A$ expression in the stomodeum; pX: Pd-WntA expression in the setal sacs. (f)-(j) details of Wnt gene expression during posterior growth. (f) Frontal optical section of a 7-day regenerate; Red arrowhead: striped Pd-Wnt5 expression in the mesoderm and ectoderm of forming segments. (g) Ventral view of a 7day regenerate showing the mesodermal expression of Pd-Wnt6. (h) Transverse section in a nascent segment of a 7-day regenerate, showing isolated cells in the gut expressing $P d-W n t 9 ;$ g: gut lumen; end: gut endoderm; gm: gut mesoderm; dlm: dorsal longitudinal muscles; vlm: ventral longitudinal muscles; vnc: ventral nerve cord; p: parapodia. (i) Ventral view of a 7-day regenerate showing parapodial expression of $P d$ WntA. (j) Close up dorsal view of nascent segments in a 7-day regenerate, showing $P d$-WntA expression in the walls of lateral vessels (red arrowheads) branching from the dorsal longitudinal vessel (dlv). The yellow dashed line in $(\mathrm{e}),(\mathrm{g})$, (i) is the approximate position of the SAZ.

\section{Acknowledgements}

APM, WMGD, GEB and RJ were funded by by the European Union via the Marie Curie Training network "ZOONET" (MRTN-CT-2004-005624). Financial funding was provided to GEB by the Swedish Natural Science Council (VR) and the Swedish Royal Academy of Sciences (KVA). The Balavoine group wishes to acknowledge the CNRS, the University Paris-Diderot, the
ANR (grant BLAN-0294) for funding. F.P. is a Research Fellow of The Terry Fox Foundation through an award from the National Cancer Institute of Canada. Work in the group of NMP is funded by the DFG (grant PR1109/ 1-1). The sequencing of Daphnia and portions of the analyses were performed at the DOE Joint Genome Institute under the auspices of the U.S. Department of Energy's Office of Science, Biological and Environmental Research Program, and by the University of California, Lawrence Livermore National Laboratory under Contract No. W-7405Eng-48, Lawrence Berkeley National Laboratory under Contract No. DE-AC02-05CH11231, Los Alamos National Laboratory under Contract No. W-7405-ENG-36 and in collaboration with the Daphnia Genomics Consortium (DGC), http://daphnia.cgb.indiana.edu. Additional analyses were performed by wFleaBase, developed at the Genome Informatics Lab of Indiana University with support to Don Gilbert from the National Science Foundation and the National Institutes of Health. Coordination infrastructure for the DGC is provided by The Center for Genomics and Bioinformatics at Indiana University, which is supported in part by the METACyt Initiative of Indiana University, funded in part through a major grant from the Lilly Endowment, Inc. Our work benefits from and contributes to the Daphnia Genomics Consortium. We thank Natália Feitosa for technical assistance, Catherine Hill for information and discussion regarding Ixodes sequences, and Nico Posnien for critical reading of the manuscript.

\section{Author details}

'Department of Earth Sciences, Palaeobiology, Villavägen 16, SE-75236 Uppsala, Sweden. ${ }^{2}$ Centre de Génétique Moléculaire du CNRS, FRE 3144, avenue de la Terrasse 91198 Gif-sur-Yvette, France. ${ }^{3}$ Georg-August-Universität Göttingen, Johann-Friedrich-Blumenbach-Institut für Zoologie und Anthropologie, Abteilung Entwicklungsbiologie, GZMB, Ernst-Caspari-Haus, Justus-von-Liebig-Weg 11, 37077 Göttingen, Germany. ${ }^{4}$ Department of Integrative Biology, University of California, Berkeley, CA 94720, USA. ${ }^{5}$ Division of Biology, Kansas State University, Manhattan, KS 66506, USA. ${ }^{6}$ Department of Organismic and Evolutionary Biology, Harvard University, 16 Divinity Ave, Cambridge MA 02138, USA. 'Institut für Populationsgenetik, Veterinärmedizinische Universität Wien, Veterinärplatz 1, A-1210, Vienna, Austria. ${ }^{8}$ The Center for Genomics and Bioinformatics, Indiana University, Bloomington, IN 47405, USA. ${ }^{9}$ Friedrich-Schiller-University Jena, Department of Genetics, Philosophenweg 12, 07743 Jena, Germany. ${ }^{10}$ Institut Jacques Monod, CNRS/Université Paris-Diderot, 15 rue Hélène Brion, 75205 Paris Cedex 13, France. ${ }^{11}$ Genzyme Corporation, One The Mountain Road, Framingham, MA 01701, USA. ${ }^{12}$ Monsanto Company, St. Louis, MO, 63107, USA.

\section{Authors' contributions}

Experiments were conceived by APM, GB, RJ, WGMD, FP, SJB and RB. Experiments were performed by RJ, MLG, GB, MP, FP, RB, ES, CH and APM. Analysis of the data was carried out by all authors. The paper was written by APM, GB, WGMD, RJ, CK and MV. All authors contributed to revising early versions of the manuscript and read the final version.

\section{Received: 21 May 2010 Accepted: 1 December 2010} Published: 1 December 2010

\section{References}

1. Logan CY, Nusse R: The Wnt signaling pathway in development and disease. Annu Rev Cell Dev Biol 2004, 20:781-810.

2. Croce JC, McClay DR: Evolution of the Wnt pathways. Methods Mol Biol 2008, 469:3-18.

3. Baker NE: Molecular cloning of sequences from wingless, a segment polarity gene in Drosophila: the spatial distribution of a transcript in embryos. EMBO J 1987, 6(6):1765-1773.

4. Ganguly A, Jiang J, Ip YT: Drosophila WntD is a target and an inhibitor of the Dorsal/Twist/Snail network in the gastrulating embryo. Development 2005, 132(15):3419-3429.

5. Graba Y, Gieseler K, Aragnol D, Laurenti P, Mariol MC, Berenger H, Sagnier T, Pradel J: DWnt-4, a novel Drosophila Wnt gene acts downstream of homeotic complex genes in the visceral mesoderm. Development 1995, 121(1):209-218.

6. Herman MA, Vassilieva LL, Horvitz HR, Shaw JE, Herman RK: The C. elegans gene lin-44, which controls the polarity of certain asymmetric cell 
divisions, encodes a Wnt protein and acts cell nonautonomously. Cell 1995, 83(1):101-110.

7. Janson K, Cohen ED, Wilder EL: Expression of DWnt6, DWnt10, and DFz4 during Drosophila development. Mech Dev 2001, 103(12):117-120.

8. Maloof JN, Whangbo J, Harris JM, Jongeward GD, Kenyon C: A Wnt signaling pathway controls hox gene expression and neuroblast migration in C. elegans. Development 1999, 126(1):37-49.

9. Rijsewijk F, Schuermann M, Wagenaar E, Parren P, Weigel D, Nusse R: The Drosophila homolog of the mouse mammary oncogene int-1 is identical to the segment polarity gene wingless. Cell 1987, 50(4):649-657.

10. Rocheleau CE, Downs WD, Lin R, Wittmann C, Bei Y, Cha YH, Ali M, Priess JR, Mello CC: Wnt signaling and an APC-related gene specify endoderm in early C. elegans embryos. Cell 1997, 90(4):707-716.

11. Russell J, Gennissen A, Nusse R: Isolation and expression of two novel Wnt/wingless gene homologues in Drosophila. Development 1992, 115(2):475-485.

12. Shackleford GM, Shivakumar S, Shiue L, Mason J, Kenyon C, Varmus HE: Two wnt genes in Caenorhabditis elegans. Oncogene 1993, 8(7):1857-1864

13. Thorpe CJ, Schlesinger A, Carter JC, Bowerman B: Wnt signaling polarizes an early $C$. elegans blastomere to distinguish endoderm from mesoderm. Cell 1997, 90(4):695-705

14. Bolognesi R, Beermann A, Farzana L, Wittkopp N, Lutz R, Balavoine G, Brown SJ, Schroder R: Tribolium Wnts: evidence for a larger repertoire in insects with overlapping expression patterns that suggest multiple redundant functions in embryogenesis. Dev Genes Evol 2008, 218(34):193-202.

15. Dearden PK, Wilson MJ, Sablan L, Osborne PW, Havler M, McNaughton E, Kimura K, Milshina NV, Hasselmann M, Gempe T, et al: Patterns of conservation and change in honey bee developmental genes. Genome Res 2006, 16(11):1376-1384.

16. Shigenobu S, Bickel RD, Brisson JA, Butts T, Chang C, Christiaens O, Davis GK, Duncan EJ, Ferrier DEK, Iga M, et al: Comprehensive survey of developmental genes in the pea aphid, Acyrthosiphon pisum: frequent lineage-specific duplications and losses of developmental genes. Insect Molecular Biology 2010, 19:47-62.

17. Cho SJ, Valles Y, Giani VC Jr, Seaver EC, Weisblat DA: Evolutionary dynamics of the Wnt gene family: a lophotrochozoan perspective. Mol Biol Evol 2010, 27:1645-1658.

18. Lengfeld T, Watanabe H, Simakov O, Lindgens D, Gee L, Law L, Schmidt HA, Ozbek S, Bode H, Holstein TW: Multiple Wnts are involved in Hydra organizer formation and regeneration. Dev Biol 2009, 330(1):186-199.

19. Prud'homme B, Lartillot $N$, Balavoine $G$, Adoutte $A$, Vervoort $M$ : Phylogenetic analysis of the Wnt gene family. Insights from lophotrochozoan members. Curr Biol 2002, 12(16):1395.

20. Garriock RJ, Warkman AS, Meadows SM, D'Agostino S, Krieg PA: Census of vertebrate Wnt genes: isolation and developmental expression of Xenopus Wnt2, Wnt3, Wnt9a, Wnt9b, Wnt10a, and Wnt16. Dev Dyn 2007, 236(5):1249-1258.

21. Kusserow A, Pang K, Sturm C, Hrouda M, Lentfer J, Schmidt HA, Technau U, von Haeseler A, Hobmayer B, Martindale MQ, et al: Unexpected complexity of the Wnt gene family in a sea anemone. Nature 2005 433(7022): 156-160

22. Lee PN, Pang K, Matus DQ, Martindale MQ: A WNT of things to come: evolution of Wnt signaling and polarity in cnidarians. Semin Cell Dev Biol 2006, 17(2):157-167.

23. Bolognesi R, Farzana L, Fischer TD, Brown SJ: Multiple Wnt genes are required for segmentation in the short-germ embryo of Tribolium castaneum. Curr Biol 2008, 18(20):1624-1629.

24. McGregor AP, Pechmann M, Schwager EE, Feitosa NM, Kruck S, Aranda M Damen WG: Wnt8 is required for growth-zone establishment and development of opisthosomal segments in a spider. Curr Biol 2008, 18(20):1619-1623.

25. Angelini DR, Kaufman TC: Functional analyses in the milkweed bug Oncopeltus fasciatus (Hemiptera) support a role for Wnt signaling in body segmentation but not appendage development. Dev Biol 2005, 283(2):409-423.

26. Ingham PW, Baker NE, Martinez-Arias A: Regulation of segment polarity genes in the Drosophila blastoderm by fushi tarazu and even skipped. Nature 1988, 331(6151):73-75
27. Martinez-Arias A, Lawrence PA: Parasegments and compartments in the Drosophila embryo. Nature 1985, 313(6004):639-642.

28. Martinez-Arias A, Baker NE, Ingham PW: Role of segment polarity genes in the definition and maintenance of cell states in the Drosophila embryo. Development 1988, 103(1):157-170.

29. Nusslein-Volhard C, Wieschaus E: Mutations affecting segment number and polarity in Drosophila. Nature 1980, 287(5785):795-801.

30. Damen WG: Parasegmental organization of the spider embryo implies that the parasegment is an evolutionary conserved entity in arthropod embryogenesis. Development 2002, 129(5):1239-1250.

31. Damen WG: Evolutionary conservation and divergence of the segmentation process in arthropods. Dev Dyn 2007, 236(6):1379-1391.

32. Janssen $R$, Budd GE, Damen WG, Prpic NM: Evidence for Wg-independent tergite boundary formation in the millipede Glomeris marginata. Dev Genes Evol 2008, 218(7):361-370.

33. Janssen R, Prpic NM, Damen WG: Gene expression suggests decoupled dorsal and ventral segmentation in the millipede Glomeris marginata (Myriapoda: Diplopoda). Dev Biol 2004, 268(1):89-104.

34. Hughes CL, Kaufman TC: Exploring myriapod segmentation: the expression patterns of even-skipped, engrailed, and wingless in a centipede. Dev Biol 2002, 247(1):47-61.

35. Prud'homme B, de Rosa R, Arendt D, Julien JF, Pajaziti R, Dorresteijn AW, Adoutte A, Wittbrodt J, Balavoine G: Arthropod-like expression patterns of engrailed and wingless in the annelid Platynereis dumerilii suggest a role in segment formation. Curr Biol 2003, 13(21):1876-1881.

36. Dray N, Tessmar-Raible K, Le Gouar M, Vibert L, Christodoulou F, Schipany K, Guillou A, Zantke J, Snyman H, Behague J, et al: Hedgehog signaling regulates segment formation in the annelid Platynereis. Science 2010, 329(5989):339-342

37. Chipman AD: Parallel evolution of segmentation by co-option of ancestral gene regulatory networks. Bioessays 2010, 32(1):60-70.

38. Couso JP: Segmentation, metamerism and the Cambrian explosion. Int J Dev Biol 2009, 53(8-10):1305-1316

39. Prpic NM: Parasegmental appendage allocation in annelids and arthropods and the homology of parapodia and arthropodia. Front Zool 2008, 5:17.

40. Peel AD, Chipman AD, Akam M: Arthropod segmentation: beyond the Drosophila paradigm. Nat Rev Genet 2005, 6(12):905-916.

41. de Rosa R, Prud'homme B, Balavoine G: Caudal and even-skipped in the annelid Platynereis dumerilii and the ancestry of posterior growth. Evol Dev 2005, 7(6):574-587.

42. van Amerongen $R$, Nusse R: Towards an integrated view of Wnt signaling in development. Development 2009, 136(19):3205-3214.

43. Prpic NM, Schoppmeier M, Damen WG: The American Wandering Spider Cupiennius salei. The Handbook of Non-Model Organisms Cold Spring Harbor Press; 2008.

44. Lawson D, Arensburger $P$, Atkinson $P$, Besansky NJ, Bruggner RV, Butler R, Campbell KS, Christophides GK, Christley S, Dialynas E, et al: VectorBase: a data resource for invertebrate vector genomics. Nucleic Acids Res 2009, 37 Database: D583-587.

45. Raible F, Tessmar-Raible K, Osoegawa K, Wincker P, Jubin C, Balavoine G, Ferrier $D$, Benes $V$, de Jong $P$, Weissenbach J, et al: Vertebrate-type intronrich genes in the marine annelid Platynereis dumerilii. Science 2005, 310(5752):1325-1326.

46. Notredame C, Higgins DG, Heringa J: T-Coffee: A novel method for fast and accurate multiple sequence alignment. J Mol Biol 2000, 302(1):205-217.

47. Gouy M, Guindon S, Gascuel O: SeaView version 4: A multiplatform graphical user interface for sequence alignment and phylogenetic tree building. Mol Biol Evol 27(2):221-224.

48. Stamatakis A, Ludwig T, Meier H: RAxML-III: a fast program for maximum likelihood-based inference of large phylogenetic trees. Bioinformatics 2005, 21(4):456-463.

49. Whelan S, Goldman N: A general empirical model of protein evolution derived from multiple protein families using a maximum-likelihood approach. Mol Biol Evol 2001, 18(5):691-699.

50. Huelsenbeck JP, Ronquist F: MRBAYES: Bayesian inference of phylogenetic trees. Bioinformatics 2001, 17(8):754-755.

51. Pechmann M, Prpic NM: Appendage patterning in the South American bird spider Acanthoscurria geniculata (Araneae: Mygalomorphae). Dev Genes Evol 2009, 219(4):189-198. 
52. Akiyama-Oda Y, Oda H: Early patterning of the spider embryo: a cluster of mesenchymal cells at the cumulus produces Dpp signals received by germ disc epithelial cells. Development 2003, 130(9):1735-1747.

53. Prpic NM, Tautz D: The expression of the proximodistal axis patterning genes Distal-less and dachshund in the appendages of Glomeris marginata (Myriapoda: Diplopoda) suggests a special role of these genes in patterning the head appendages. Dev Biol 2003, 260(1):97-112.

54. Klingler M, Gergen JP: Regulation of runt transcription by Drosophila segmentation genes. Mech Dev 1993, 43(1):3-19.

55. Brown SJ, Parrish JK, Beeman RW, Denell RE: Molecular characterization and embryonic expression of the even-skipped ortholog of Tribolium castaneum. Mech Dev 1997, 61(1-2):165-173.

56. Tautz $D$, Pfeifle $C$ : A non-radioactive in situ hybridization method for the localization of specific RNAs in Drosophila embryos reveals translational control of the segmentation gene hunchback. Chromosoma 1989, 98(2):81-85.

57. Tessmar-Raible K, Steinmetz PR, Snyman H, Hassel M, Arendt D: Fluorescent two-color whole mount in situ hybridization in Platynereis dumerilii (Polychaeta, Annelida), an emerging marine molecular model for evolution and development. Biotechniques 2005, 39(4):460-464

58. McGregor AP, Hilbrant M, Pechmann M, Schwager EE, Prpic NM, Damen WG: Cupiennius salei and Achaearanea tepidariorum: Spider models for investigating evolution and development. Bioessays 2008, 30(5):487-498.

59. Nusse R: An ancient cluster of Wnt paralogues. Trends Genet 2001, 17(8):443.

60. Sullivan JC, Ryan JF, Mullikin JC, Finnerty JR: Conserved and novel Wnt clusters in the basal eumetazoan Nematostella vectensis. Dev Genes Evol 2007, 217(3):235-239.

61. Nagy LM, Carroll S: Conservation of wingless patterning functions in the short-germ embryos of Tribolium castaneum. Nature 1994, 367(6462):460-463.

62. Nulsen C, Nagy LM: The role of wingless in the development of multibranched crustacean limbs. Dev Genes Evol 1999, 209(6):340-348.

63. Janssen R, Damen WG: Diverged and conserved aspects of heart formation in a spider. Evol Dev 2008, 10(2):155-165.

64. Llimargas M, Lawrence PA: Seven Wnt homologues in Drosophila: a case study of the developing tracheae. Proc Natl Acad Sci USA 2001, 98(25):14487-14492.

65. Zinovyeva AY, Yamamoto $Y$, Sawa H, Forrester WC: Complex network of Wnt signaling regulates neuronal migrations during Caenorhabditis elegans development. Genetics 2008, 179(3):1357-1371.

66. Gleason JE, Szyleyko EA, Eisenmann DM: Multiple redundant Wnt signaling components function in two processes during $C$. elegans vulval development. Dev Biol 2006, 298(2):442-457.

67. Gieseler K, Graba Y, Mariol MC, Wilder EL, Martinez-Arias A, Lemaire P, Pradel J: Antagonist activity of DWnt-4 and wingless in the Drosophila embryonic ventral ectoderm and in heterologous Xenopus assays. Mech Dev 1999, 85(1-2):123-131.

68. Fradkin LG, Noordermeer JN, Nusse R: The Drosophila Wnt protein DWnt3 is a secreted glycoprotein localized on the axon tracts of the embryonic CNS. Dev Biol 1995, 168(1):202-213.

69. Guder C, Philipp I, Lengfeld T, Watanabe H, Hobmayer B, Holstein TW: The Wnt code: cnidarians signal the way. Oncogene 2006, 25(57):7450-7460

70. Buratovich MA, Anderson S, Gieseler K, Pradel J, Wilder EL: DWnt-4 and Wingless have distinct activities in the Drosophila dorsal epidermis. Dev Genes Evol 2000, 210(3):111-119.

71. Snodgrass RE: Evolution of Annelida, Onychophora and Arthropoda. Smithsonian Miscellaneous Collections 1938, 138:1-77.

72. Liu PZ, Kaufman TC: Short and long germ segmentation: unanswered questions in the evolution of a developmental mode. Evol Dev 2005, 7(6):629-646.

73. Davis GK, Patel NH: Short, long, and beyond: molecular and embryological approaches to insect segmentation. Annu Rev Entomol 2002, 47:669-699.

74. Miyawaki K, Mito T, Sarashina I, Zhang H, Shinmyo Y, Ohuchi H, Noji S Involvement of Wingless/Armadillo signaling in the posterior sequential segmentation in the cricket, Gryllus bimaculatus (Orthoptera), as revealed by RNAi analysis. Mech Dev 2004, 121(2):119-130

75. Bolognesi R, Fischer TD, Brown SJ: Loss of Tc-arrow and canonical Wnt signaling alters posterior morphology and pair-rule gene expression in the short-germ insect, Tribolium castaneum. Dev Genes Evol 2009, 219(7):369-375.

76. Li HY, Bourdelas A, Carron C, Gomez C, Boucaut JC, Shi DL: FGF8, Wnt8 and Myf5 are target genes of Tbx6 during anteroposterior specification in Xenopus embryo. Dev Biol 2006, 290(2):470-481.

77. Shimizu T, Bae YK, Muraoka O, Hibi M: Interaction of Wnt and caudalrelated genes in zebrafish posterior body formation. Dev Biol 2005, 279(1):125-141.

78. Takada S, Stark KL, Shea MJ, Vassileva G, McMahon JA, McMahon AP: Wnt$3 a$ regulates somite and tailbud formation in the mouse embryo. Genes Dev 1994, 8(2):174-189.

79. Thorpe CJ, Weidinger G, Moon RT: Wnt/beta-catenin regulation of the Sp1-related transcription factor sp5l promotes tail development in zebrafish. Development 2005, 132(8):1763-1772.

80. Martin BL, Kimelman D: Wnt signaling and the evolution of embryonic posterior development. Curr Biol 2009, 19(5):R215-219.

81. McGregor AP, Pechmann M, Schwager EE, Damen WG: An ancestral regulatory network for posterior development in arthropods. Commun Integr Biol 2009, 2(2):174-176.

82. Rivera AS, Gonsalves FC, Song MH, Norris BJ, Weisblat DA: Characterization of Notch-class gene expression in segmentation stem cells and segment founder cells in Helobdella robusta (Lophotrochozoa; Annelida; Clitellata; Hirudinida; Glossiphoniidae). Evol Dev 2005, 7(6):588-599

83. Rivera AS, Weisblat DA: And Lophotrochozoa makes three: Notch/Hes signaling in annelid segmentation. Dev Genes Evol 2009, 219(1):37-43.

84. Tomer R, Denes AS, Tessmar-Raible K, Arendt D: Profiling by image registration reveals common origin of annelid mushroom bodies and vertebrate pallium. Cell 2010, 142(5):800-809.

85. Gordon MD, Dionne MS, Schneider DS, Nusse R: WntD is a feedback inhibitor of Dorsal/NF-kappaB in Drosophila development and immunity. Nature 2005, 437(7059):746-749.

86. van Ooyen A, Kwee V, Nusse R: The nucleotide sequence of the human int-1 mammary oncogene; evolutionary conservation of coding and non-coding sequences. EMBO J 1985, 4(11):2905-2909.

87. Wainwright BJ, Scambler PJ, Stanier P, Watson EK, Bell G, Wicking C, Estivill X, Courtney M, Boue A, Pedersen PS, et al: Isolation of a human gene with protein sequence similarity to human and murine int- 1 and the Drosophila segment polarity mutant wingless. EMBO J 1988, 7(6):1743-1748

88. Katoh M, Hirai M, Sugimura T, Terada M: Cloning, expression and chromosomal localization of Wnt-13, a novel member of the Wnt gene family. Oncogene 1996, 13(4):873-876.

89. Nusse R, Brown A, Papkoff J, Scambler P, Shackleford G, McMahon A, Moon $\mathrm{R}$, Varmus $\mathrm{H}$ : A new nomenclature for int- 1 and related genes: the Wnt gene family. Cell 1991, 64(2):231.

90. Saitoh T, Hirai M, Katoh M: Molecular cloning and characterization of WNT3A and WNT14 clustered in human chromosome 1q42 region. Biochem Biophys Res Commun 2001, 284(5):1168-1175.

91. Smolich BD, McMahon JA, McMahon AP, Papkoff J: Wnt family proteins are secreted and associated with the cell surface. Mol Biol Cell 1993, 4(12):1267-1275.

92. Clark CC, Cohen I, Eichstetter I, Cannizzaro LA, McPherson JD, Wasmuth JJ, lozzo RV: Molecular cloning of the human proto-oncogene Wnt-5A and mapping of the gene (WNT5A) to chromosome 3p14-p21. Genomics 1993, 18(2):249-260

93. Saitoh $\mathrm{T}$, Katoh M: Molecular cloning and characterization of human WNT5B on chromosome 12p13.3 region. Int J Oncol 2001, 19(2):347-351

94. Gavin BJ, MCMahon JA, McMahon AP: Expression of multiple novel Wnt-1/ int-1-related genes during fetal and adult mouse development. Genes Dev 1990, 4(12B):2319-2332.

95. Ikegawa S, Kumano Y, Okui K, Fujiwara T, Takahashi E, Nakamura Y: Isolation, characterization and chromosomal assignment of the human WNT7A gene. Cytogenet Cell Genet 1996, 74(1-2):149-152

96. van Bokhoven $H$, Kissing J, Schepens M, van Beersum S, Simons A, Riegman P, McMahon JA, McMahon AP, Brunner HG: Assignment of WNT7B to human chromosome band $22 q 13$ by in situ hybridization. Cytogenet Cell Genet 1997, 77(3-4):288-289.

97. Saitoh T, Katoh M: Molecular cloning and characterization of human WNT8A. Int J Oncol 2001, 19(1):123-127. 
98. Lako M, Strachan T, Curtis AR, Lindsay S: Isolation and characterization of WNT8B, a novel human Wnt gene that maps to 10q24. Genomics 1996 35(2):386-388

99. Bergstein I, Eisenberg LM, Bhalerao J, Jenkins NA, Copeland NG,

Osborne MP, Bowcock AM, Brown AM: Isolation of two novel WNT genes, WNT14 and WNT15, one of which (WNT15) is closely linked to WNT3 on human chromosome 17q21. Genomics 1997, 46(3):450-458.

100. Kirikoshi H, Sekihara H, Katoh M: WNT10A and WNT6, clustered in human chromosome 2q35 region with head-to-tail manner, are strongly coexpressed in SW480 cells. Biochem Biophys Res Commun 2001, 283(4):798-805.

101. Hardiman G, Kastelein RA, Bazan JF: Isolation, characterization and chromosomal localization of human WNT10B. Cytogenet Cell Genet 1997, 77(3-4):278-282.

102. Lako M, Strachan T, Bullen P, Wilson DI, Robson SC, Lindsay S: Isolation, characterisation and embryonic expression of WNT11, a gene which maps to $11 \mathrm{q} 13.5$ and has possible roles in the development of skeleton, kidney and lung. Gene 1998, 219(1-2):101-110.

103. McWhirter JR, Neuteboom ST, Wancewicz EV, Monia BP, Downing JR, Murre $\mathrm{C}$ : Oncogenic homeodomain transcription factor $\mathrm{E} 2 \mathrm{~A}-\mathrm{Pbx} 1$ activates a novel WNT gene in pre-B acute lymphoblastoid leukemia. Proc Natl Acad Sci USA 1999, 96(20):11464-11469.

doi:10.1186/1471-2148-10-374

Cite this article as: Janssen et al.: Conservation, loss, and redeployment of Wnt ligands in protostomes: implications for understanding the evolution of segment formation. BMC Evolutionary Biology 2010 10:374.

\section{Submit your next manuscript to BioMed Central and take full advantage of:}

- Convenient online submission

- Thorough peer review

- No space constraints or color figure charges

- Immediate publication on acceptance

- Inclusion in PubMed, CAS, Scopus and Google Scholar

- Research which is freely available for redistribution

Submit your manuscript at www.biomedcentral.com/submit 